\title{
A Systematic Mapping Study of HCI Practice Research
}

\begin{abstract}
Human Computer Interaction (HCI) practice has emerged as a research domain in the HCI field and is growing. The need to transfer HCI practices to the industry began significantly with the works of Nielsen on usability engineering. To date, methods, and techniques for designing, evaluating and implementing interactive systems for human use have continued to emerge. It is, therefore, justified to conduct a systematic mapping study to determine the landscape of HCI practice research. A Systematic Mapping Study method was used to map 142 studies according to research type, topic, and contribution. These were then analyzed to determine an overview of HCI practice research. The objective was to analyze studies on HCI practice and present prominent issues that characterize the HCI practice research landscape. Secondly, to identify pressing challenges regarding HCI practices in software/systems development companies. The results show that HCI practice research has steadily increased since 2012. The majority of the studies explored focused on evaluation research that largely contributed to evaluation methods or processes. Most of the studies were on design tools and techniques, design methods and contexts, design work and organizational culture, and collaboration and team communication. Interviews, case studies, and survey methods have been prominently used as research methods. HCI techniques are mostly used during the initial phase of development, and during evaluation. HCI practice challenges in companies are mostly process-related and on performance of usability and UX activities. The major challenge seems to be to find a way to collect and incorporate user feedback in a timely manner, especially in agile processes. There are areas identified in this study as needing more research.
\end{abstract}

This is an Author's Original Manuscript of an article published by Taylor \& Francis Group in International Journal of Human-Computer Interaction on 08/11/2018, available online: https://www.tandfonline.com/doi/full/10.1080/10447318.2018.1541544

\section{Introduction}

Human Computer Interaction (HCI) practice has emerged as a research domain in the field of Human-Computer Interaction and is growing. However, the research landscape in HCI practice is still not so clear. Furthermore, it is well documented in the existing literature that there are low uptakes of HCI practices in software development companies.

Combinations of methods such as field studies are used in practice research. Practice research can be practice-based research in which the new knowledge results in creating an artifact, or practice-led research in which new understandings about practice are achieved (Candy, 2006). HCI practice research tends to be both practice-based and practice-led. Vermeeren and Cockton (2013) used the Rogers' theory of innovation diffusion to propose how new HCI methods could be transferred successfully to work practice. Ogunyemi, Lamas, Adagunodo, and Rosa (2015) investigated the state of usability and user experience practices in the Nigerian software industry and found that the level of HCI awareness is low because very few Nigerian universities that offer HCI courses have elementary focus on HCI. It was also reported that a lack of distinction between users and customers existed in some companies. Similarly, Ardito, Buono, Caivano, Costabile, and Lanzilotti (2014) investigated the state of user experience (UX) practice in Italian software companies and found companies either still ignore usability and UX aspects in projects or merely conduct these practices on a low scale. Chilana, Ko, Wobbrock, Grossman, and Fitzmaurice (2011) investigated post-deployment usability activities and the state of user-centred design practice among 333 full time usability professionals and consultants and found that usability professionals are not being so 
much involved post-deployment usability activities compared to other user-centered development phases. In another study, Chilana, Ko, and Wobbrock (2015) found the user-centred design method is disconnected from wide focus on the stakeholders because of its sole focus on the user, and therefore, proposed the adoption-centred design method. The rationale is that users are not usually the buyers of the product. This is especially so for non-consumer products.

HCI practice began to emerge as a necessity for development companies with the efforts of Nielsen on usability engineering (Nielsen, 1993). There was a need to transfer HCI practice to industry. Nielsen argued that since $48 \%$ of coding effort is used for user interface design (Myers \& Rosson, 1992), it should be proportionally so, that the usability of user interfaces is prioritized. Shortly after Nielsen's introduction of usability engineering to development companies, a vision by Winograd (1997) suggested that computing as a discipline would shift to interaction due to the need to focus on people rather than machinery. Winograd (1997) foresaw the emergence of methods, skills, and techniques because of this focus on people. Since then, new design methods, techniques, and concepts have continued to emerge in the field of HCI, and interaction design is becoming a core focus for designers and companies.

One of the prominent design approaches in HCI is user-centred design (UCD). The UCD approach was first mentioned by Donald Norman and UCD began to gain prominence after Norman jointly authored the book "User-Centered System Design: New Perspectives on Human-Computer Interaction" with Stephen Draper in 1986 (Norman \& Draper, 1986). User-centred design is a process design approach, and has been successfully researched and integrated at least to agile processes such as SCRUM and Kanban (See e.g. (Law \& Lárusdóttir, 2015; Maguire, 2013; Sy, 2007)).

One important technique of the human-centred design ${ }^{1}$ approach is design thinking, and has been popularised by IDEO and IBM. Design thinking is a design technique whose goal is to solve a specific problem by bringing different stakeholders on board. According to Rosenberg (2014) design thinking is a "creative problem-solving approach rooted in a model of human empathy, brainstorming methods, prototyping, and iteration" (p.75). Brown (2009) explained that design thinking is human-centred because of the balance it establishes regarding users, technology, and business' perspectives. Zimmerman, Forlizzi, and Evenson (2007) observed that design thinking is rarely defined and this can be seen in existing literature where some authors merely mention the technique without describing the essence of its use or applicability. For this reason, Zimmerman, Forlizzi, and Evenson (2007) define design thinking as:

"The application of a design process that involves grounding-investigation to gain multiple perspectives on a problem; ideation - generation of many possible different solutions; iteration - cyclical process of refining concept with increasing fidelity; and reflection" (p.494).

From this definition it can be seen that design thinking applies a design process that begins with establishing a problem, then continues by ideating, iterating, and reflecting. Design thinking has also been viewed as an approach that firms could use to innovate and

${ }^{1}$ User-centred design and human-centred design are used interchangeably in the existing HCI literature. 
gain competitive edge (Brown, 2008; D'Ippolito, 2014; Liem \& Sanders, 2011). In particular Brown (2008) stated that the goal of design thinking is disruptive innovation for gaining competitive edge in the global market. People other than designers can conduct design thinking ((Brown, 2008) cited in D'Ippolito (2014)). Furthermore, Rosenberg (2014) believes design thinking can be viewed "as a philosophy, a methodology, and a value-creation model." Nevertheless, Liem and Sanders (2011) noted that the design-led perspective of design thinking does not place value on the end-users as a stakeholder in the early front end of the process unlike the co-creation perspective that "puts the tools and methods of design thinking into the hands of the people who will be the future end-users (and the other stakeholders) early in the front end of the product development process" (p.113). In the same vein, Zoltowski (2010) argued that understanding the people being affected by the design is a crucial aspect of design thinking. For this reason, Mcginley and Macredie (2011) submit that:

"When access to diverse user groups is unavailable, information about the groups has to be available instead - and it has to be in a format that is accessible and is perceived as having value by designers" (p.5).

A systematic mapping study produces a layout of research types. The results are obtained by categorization and the report generates a visual summary, which is the map of the results. The systematic mapping study method has been employed to provide a good overview of a research domain (Petersen, Feldt, Mujtaba, \& Mattsson, 2008) and supports undertaking software engineering-related research needs (Kitchenham \& Charters, 2007); thus, a systematic mapping study is selected as the most suitable way to harness the structure of research of HCI practice in a systematic way. One of the major differences between a systematic review and systematic mapping study is that unlike systematic reviews, systematic maps do not need assessment of quality of included papers (Petersen, Vakkalanka, \& Kuzniarz, 2015). Therefore, this study would not assess the quality of the included papers.

This study aims to explore existing studies on HCI practice and produce a systematic map that shows an indication of what methods and techniques have been used and to what extent based on a carefully identified sample from the literature. There is an increase in recognition of HCI practices in software development companies and HCI influences several software engineering (SE) processes today (Ferre \& Moreno, 2004). The findings of the study are beneficial to HCI researchers aiming to promote an HCI related approach in companies, as well as novice HCI researchers who need to situate themselves into HCI practice research. The outcomes provide some implications for research and practice. For HCI practice researchers, the HCI practice research landscape can be perceived more clearly, have insight to choose appropriate research methods for research works, be made aware of related works, and channel a better course for future research. HCI and software practitioners can benefit for example, from the taxonomy of HCI design techniques, and methods, which was carefully structured into three phases that would fit in the entire development lifecycle. Practitioners are also equipped with knowledge of the taxonomy and could learn more about these HCI approaches.

This paper is organized as follows. In the next section we provide a brief theoretical background to our study. In section 3 we describe our research method. In section 4, we present our classification scheme. Next we present the results and in section 6 we discuss the results, and provide implications for research and practice. Finally, we conclude the work and present directions for future work. 


\section{Background}

There still appears to be a lack of coordination in HCI practices of how techniques and methods are being applied to software development processes and what challenges are being experienced. The term 'HCI practice' has been used loosely in many of the previous research works and there appears to be no clear understanding of what HCI practice actually entails. In order to articulate our thoughts, we would offer a definition of HCI practice. The vast amount of existing papers on HCI practice have described approaches used to conduct design, evaluation, and implementation of interactive systems people would use. We would, therefore, describe HCI practice as the application of HCI concepts, HCI techniques or methods to the process of analyzing, designing, evaluating and implementing interactive systems for human use. In this section, we situate the reader by providing an overview of HCI practice, taking a closer look at concepts, techniques or methods for $\mathrm{HCI}$, which are core to its practice. We also present related studies and provide a justification for the need for a systematic mapping study such as ours.

\subsection{HCI concepts, techniques or methods}

We define an HCI concept as an abstract or generic idea derived and inferred from specific situations. The essence of using HCI concepts is to give meaning to design and cause a desired action to be produced. HCI concepts are becoming a bedrock of knowledge to assist practitioners in software development processes because HCI concepts focus on the user while designing interactive systems (Sousa \& Furtado, 2003). Usability is an important concept in HCI (Rex Hartson, 1998; Rozanski \& Haake, 2003; Zapata, 2015). It has been observed that the majority of software engineers are not trained in HCI and they possess little or no knowledge of how to apply HCI concepts in their technical activities (Bruun \& Stage, 2012; Ludi, 2003). This view was earlier corroborated by Walenstein (2003) when he noted that creating awareness of HCI concepts and meanings for software engineering professionals is difficult due to educational differences. A recent study also corroborates the fact that HCI knowledge should be promoted among software developers (Øvad \& Larsen, 2016). In their work, Sousa and Furtado (2003) presented a workflow called 'RUPi', which is based on four concepts; that is, human factors, guidelines, user interface for all, model-based UI generation. The study further shows how the four concepts could help to perform activities leading to production of artifacts that consider human factors, usability requirements, accessibility and acceptability, usability evaluation, and graphical scenarios generation when developing interactive systems for human use. Although HCI concepts are useful for designing interactive systems, not all are fitting to industrial practice. A notable example was provided in the work by Sener and Wormald (2008) in which 11 novel concepts had to be created for the purpose of form creation. The reason for creating new concepts was to react to the challenges expressed by industrial designers. It was reported that industrial designers could not apply Computer-Aided Design (CAD) to the design of industrial forms. A concept could only have excellent properties if those properties are implementable (Hudson \& Mankoff, 2014). One of the concepts, which are central to HCI design, is that of value. Values are a block of emotional attributes anticipated by the system's stakeholders, meant to drive system development. Values do not necessarily focus on sales and profit, but also for a personal, political, cultural, organizational or religious purpose, depending on what is deemed valued by a 
stakeholder of a system (Cockton, 2004). To date, the development of interactive systems by software development companies is being limited by a lack of consideration of human values. Usability is perhaps not the only important consideration for the development of interactive systems, other values such as products' accessibility, affordability, enjoyability, sustainability, noticeability, appropriateness, among others have over the years become very important. Today's interactive systems have gone beyond usability and usability has been sufficiently researched in the HCI community. Accessibility of interactive systems is considered important to support people with certain disabilities (Hudson \& Mankoff, 2014). Laws and guidelines have been promoted to enforce accessibility in designs especially for web-based systems and accessibility design require more than informal evaluation, ad-hoc quality testing activities (Molina \& Toval, 2009). Appropriation of a system to a given context based on particular needs is important when considering voluntary adoption (Hayes, 2014).

HCI techniques or methods, just like HCI concepts, are important knowledge blocks for practitioners. The field of HCI has for more than three decades focused on the design, evaluation and implementation of interactive systems for human use and has developed several techniques and methods, which can be applied to achieve the development of usable systems for people. To date, techniques or methods such as the think aloud protocol, personas, scenarios, wire frames, Wizard of Oz, software usability scales, card sorting, heuristic evaluation, participatory design, user-centred design, and humancentred design have been reported in the literature. However, there still appears to be a lack of coordination in HCI practices of how techniques or methods are being applied to software development processes and what challenges are being experienced. HCI techniques or HCI methods have similar meanings within the literature and are used interchangeably by HCI researchers.

Personas, scenarios, storyboards, and visual brainstorming were cited by Ferre and Medinilla (2007), as examples of HCI techniques. Ferre and Medinilla went ahead to stress that HCI techniques have to be dynamically applied for as long as approaches to interactive systems development continue to change. Similarly, Downey (2007) described five formative usability testing techniques namely; co-discovery, individual usability testing, cooperative usability testing, task-based focus groups, and group usability testing. Hochheiser and Lazar (2007) described participatory design, contextual inquiry, and paper prototypes also as HCI techniques. Bødker and Christiansen (2004) gave examples of paper mockups, and video prototyping as well as HCI techniques.

Nivala, Tiina Sarjakoski, and Sarjakoski (2007) described user-centred design and usability engineering as HCI methods. The authors, in particular, indicated that usability engineering is a term used for describing methods for making software usable and enumerated interviews, surveys, contextual inquiry, focus groups, brainstorming, as examples of usability engineering methods. Similarly, Majid, Noor, Adilah, and Adnan (2012) described user-centred design, usability engineering, and participatory design as HCI methods. The authors reiterate the fact that some researchers had used different terms such as approach, process, method, concept, and technique to refer to user-centred design, usability engineering, human-centred design, and participatory design. Similarly, Dighe and Joshi (2014), referring to previous works, described usability engineering, and human-centred design as HCI methods. 
From the foregoing, we perceive 'HCI techniques' and 'HCI methods' as two congenial terms used interchangeably by HCI researchers. The focus has not really been on whether there should be a distinction between the two terms, but rather that researchers are prone to using the two terms to describe approaches for analyzing, designing and evaluating interactive systems; albeit some techniques or methods being low cost and fast to use and some not. Therefore, we do not want to distinguish between these two terms but believe they are being used interchangeably. Both a "technique" and a "method" are ways of doing things.

\subsection{Related studies}

Systematic review and mapping studies have increased in recognition among scholars in HCI and SW engineering disciplines (Kitchenham \& Charters, 2007). Salvador, Nakasone, and Pow-Sang (2014) conducted a systematic review study on usability techniques in agile methodologies. The aim of the study was to synthesize existing studies on usability techniques in agile methodologies and identify what is the scope of the current works on the discourse and what areas require attention for future research. The outcomes of the study indicate that complementary usability techniques are used with agile methodologies and evaluation is conducted at the implementation stage only. There is a huge risk considering the cost of fixing post-deployment usability issues. Evaluations are mainly in the form of case studies. Although the study by Salvador et al. (2014) provided useful insights regarding usability techniques, we also need to know what happens at the different phases of development where HCI approaches are being applied.

In their study, Fernandez, Insfran, and Abrahão (2011) examined 206 papers and found $39 \%$ of usability evaluation methods specifically targeted for web development. The study revealed that user testing is the method mostly used for evaluation. The study provided quality maps, which could be used to undertake research on usability evaluation methods for web application. However, just like the study by Salvador et al. (2014), the major difference with our aim is that the scope of Fernandez et al. (2011) is limited to evaluation of web applications.

Brhel, Meth, Maedche, and Werder (2015) conducted a systematic review of user-centred agile software development and the goal was to identify principles that constitute usercentred agile software development (UCASD). The study identified five broad principles for UCASD and these could be utilized in software development processes and practices. The five principles are perceived to be important for the design of useful and usable software. Three of the five principles are regarding the development process and they are: a) separate product discovery and product creation; b) iterative and incremental design and development; and c) parallel interwoven creation tracks. The remaining two principles are continuous stakeholder involvement, and artifact-mediated communication and are defined as practices for the principles of UCASD.

Bertholdo, Da Silva, De O. Melo, Kon, and Silveira (2014) examined existing literature on agile and UCD methods and observed there was a gap regarding the practice with agile UCD methods. Based on the identified gap, Bertholdo et al. (2014) proposed agile usability patterns for the early stages of UCD. The proposal is to foster practitioners' understanding of the contexts of applying the agile usability patterns and to bring out the problems that can be experienced within varying contexts. The study by Bertholdo et al. 
(2014) improved our understanding regarding contexts of applying UCD methods. However, being a review, there is still need for a more systematic approach and mapping studies regarding HCI practices. Similar to the work of Bertholdo et al. (2014), there was an indication that the context of use of a system is majorly overlooked. For that reason Mosqueira-Rey, Alonso-Ríos, and Moret-Bonillo (2009) proposed a usability taxonomy that describes context of use and relevant attributes in a more holistic manner. The major limitation of their study is that it lacked a systematic approach and, therefore, weak methodologically. In a survey and a closely related study, Bark, Følstad, and Gulliksen (2006) explored the use and usefulness of HCI methods among 179 HCI practitioners from the Nordic countries. The goals of the study were to understand which HCI methods HCI practitioners perceived as most useful in varying projects stages and to identify if ICT project types have any impact on HCI practitioners' perceptions. In the study, project phases were divided into start, mid, and end phases and 20 different HCI methods were grouped into these. HCI methods aimed at systems planning, analysis and specifications were grouped under the start phase, design was grouped under the mid phase, and evaluation was grouped under the end phase. Field studies and interviews were perceived as the most used methods in the start phase. User tests and rapid prototyping were perceived as the most used methods in the mid phase, while user testing followed by expert evaluation were rated the most used methods in the end phase. We argue that the contribution Bark et al. (2006) provided a lot of insights into HCI practices in software engineering processes and projects, albeit nothing is still known about the classification of HCI work practices and studies of this nature are to date, very scarce. There is a need to extend the scope of the work of Bark et al. (2006) by conducting a systematic mapping study to achieve a comprehensive understanding of HCI practice and guide future research.

Four out of the six related studies were based on usability evaluation and analysis. Usability is considered a central topic in HCI (Rex Hartson, 1998; Rozanski \& Haake, 2003) and is gaining attention in the SE community (Mosqueira-Rey et al., 2009). All the six studies provide a good overview of usability practice in companies and reveal various methods and techniques that are in use and various stages in the lifecycle where these approaches are being used. It can only be expected that there are better approaches to design and development of interactive systems with these kinds of contributions.

\subsection{The need for a systematic mapping study}

Although the definitions are clear regarding what constitutes aspects of HCI practices, the overarching concern is that HCI practices papers vary in terms of application (processes, users, organizations, projects) as well as purpose (description, prediction, prescription). Thus, we look closely at HCI practices from three perspectives:

1. Description of design concepts, techniques, or methods;

2. Analysis of design concepts, techniques, or methods in order to predict patterns of user behaviour and experience as a result of actual or anticipated interaction with systems;

3. Evaluation of design concepts, techniques, or methods in order to prescribe solutions to problems being encountered as a result of the application of these approaches to the development of interactive systems and the user experience. 
We have taken these three perspectives from the ACM definition of human-computer interaction (Hewett et al., 1996). The core elements of the definition are design, evaluation, and implementation.

This study is important in order to foster our knowledge regarding HCI practices in software development companies. Considering the amount of research results produced in the field and the fact that there is still low awareness and knowledge of HCI in development companies, we need to know what characterizes HCI practices in companies and what challenges are being experienced. We as researchers require a clear focus regarding HCI practices in the industry for the ability to conceptualize these practices and set clear foundations of their structure and process.

Table 1

Systematic mapping study process adapted form Paternoster, Giardino, Unterkalmsteiner, Gorschek, and Abrahamsson (2014). Note that the underlying procedure has been adapted from Petersen et al. (2008)

\begin{tabular}{lllllll}
\hline $\begin{array}{l}\text { Steps for } \\
\text { the } \\
\text { process }\end{array}$ & $\begin{array}{l}\mathbf{3 . 1} \\
\text { Define } \\
\text { research } \\
\text { questions }\end{array}$ & $\mathbf{3 . 2}$ Search & $\begin{array}{l}\mathbf{3 . 3} \\
\text { Inclusion } \\
\text { and } \\
\text { exclusion } \\
\text { of papers }\end{array}$ & $\begin{array}{l}\mathbf{3 . 4} \\
\text { Classification } \\
\text { process }\end{array}$ & $\begin{array}{l}\text { 3.5 } \\
\text { Extract } \\
\text { data and } \\
\text { map }\end{array}$ & $\begin{array}{l}\text { Synthesize } \\
\text { results }\end{array}$ \\
\hline Outcomes & $\begin{array}{l}\text { Study } \\
\text { scope } \\
\text { review }\end{array}$ & $\begin{array}{l}\text { Search for } \\
\text { all papers in } \\
\text { relevant } \\
\text { sources }\end{array}$ & $\begin{array}{l}\text { Obtain } \\
\text { relevant } \\
\text { papers }\end{array}$ & $\begin{array}{l}\text { Classify } \\
\text { scheme }\end{array}$ & Produce & Classify \\
& & & & systematic \\
maps & $\begin{array}{l}\text { HCI } \\
\text { practices } \\
\text { and } \\
\text { challenges }\end{array}$ \\
\hline
\end{tabular}

\section{Method}

"If I have seen further than others, it is by standing upon the shoulders of giants" - Sir Isaac Newton $(1642$ - 1727) 2 .

We have followed the guidelines described by Kitchenham and Charters (2007) as well as the systematic mapping procedure by Petersen et al. (2008) and Petersen et al. (2015) to conduct this systematic mapping study. We favored a systematic mapping study ahead of a systematic review study. Our desire is to explore HCI practice based on a carefully identified sample of studies from the literature. A systematic mapping study helps to derive a visual summary, and "a more coarse-grained overview" of research studies thereby providing a clear structure of a research domain (Petersen et al., 2008). Thus, we are inspired that a systematic mapping study would allow us to indicate what methods and techniques have been used and to what extent based on carefully identified sample from the literature.

\subsection{Research questions}

The questions drawn in this study have been framed based on three components proposed by Kitchenham and Charters (2007) and adapted from Neto, MacHado, McGregor, De Almeida, and Meira (2011).

1. Population: peer-reviewed literature on HCI practices;

\footnotetext{
2 Source: The Internet
} 
2. Intervention: empirical studies on HCI practice, that is, concepts, techniques or methods, in relation to software development processes or projects;

3. Outcomes: Type and quantity of evidence relating to various HCI practices, in order to identify research trends in this domain.

Based on the three components therefore, and in order to address the broad aim of this study, the questions raised are presented in Table 2 .

Table 2

Research questions and goals

$\begin{array}{ll}\text { Research Questions } & \text { Goals }\end{array}$

RQ1. How are HCI practice papers distributed over the years and in what venues?

To determine the progression of HCI practice papers and where they can be majorly found.

RQ2. What types of papers are published in the topic areas and what type of evaluation and contribution do they offer?

To have a broad overview of what characterizes HCI practice in terms of research type, contribution, and topic focus.

RQ3. What research methods have been mostly applied in HCI practice researches?

To determine which research methods have been used mostly by researchers and understand whether or not a specific method could be more relevant than the others when conducting $\mathrm{HCI}$ practice research.

RQ4. What HCI techniques have been reported in the current literature regarding $\mathrm{HCI}$ practice and in what context of use?

To determine which techniques are mostly frequently used and the context of their use.

RQ5. In what development project areas have HCI practice been applied as documented in the existing literature?

To identify to which development kinds are HCI practice been commonly applied.

RQ6. What challenges have been reported in software development companies regarding HCI practices?

To identify pressing challenges regarding HCI practices in development companies that could be interesting for future research.

\subsection{Literature Search}

In line with the frame of components presented in Table 1, we searched digital libraries in order to identify our primary objectives. We explored combinations of various keywords in order to derive a search string. The core concepts of HCI practice are usability engineering and interaction design and the keywords presented as terms in Table 3 were derived from these two concepts. The keywords (terms) are associated with papers on HCI practice and not HCI practice on their own. The search string is simple and is presented in Table 3 .

Table 3

Search strings 


\begin{tabular}{ll}
\hline Concepts & Keywords \\
\hline HCI Practice & $\begin{array}{l}\text { usability*; human-centred design*; evaluation technique*; user-experience*; } \\
\text { user-centred design*; hci practice*; }\end{array}$ \\
Development Process & $\begin{array}{l}\text { agile software engineering*; software*; practitioner*; post-deployment } \\
\text { evaluation*; software industry*; software process*; process*; practice*; } \\
\text { method*; methodology*; }\end{array}$ \\
\hline
\end{tabular}

The keywords were from our research questions. Our search was conducted for literature up until 31 July 2016. Table 4 is the presentation of the digital sources on which we have conducted our search. The databases were selected because articles relating to HCI and $\mathrm{SE}$ are found in them. We also looked at previous systematic studies such as Inayat, Salwah, Marczak, Daneva, and Shamshirband (2015) and Paternoster et al. (Paternoster et al., 2014) to draw our inspiration regarding sources to look for HCI and SE articles.

Table 4

Papers retrieved from selected digital libraries

\begin{tabular}{lll}
\hline S/N & Digital Library/Database & \# Papers \\
\hline ACM & 604 \\
IEEE Xplore & 10 \\
Springer & 742 \\
ScienceDirect & 125 \\
Taylor and Francis & 651 \\
Wiley Online & 236 \\
Scopus & 16 \\
Total & 2384 \\
\hline
\end{tabular}

\subsection{Inclusion and exclusion of papers}

The criteria set for including a paper are that such paper is peer-reviewed, empirical, written in English, published between 2000 and 2016 and must show a clear connection between certain HCI concept, or technique, or methods being applied or integrated to software/system development processes or projects in practice. Non-empirical papers such as experience papers, opinion papers, philosophical papers, and solution papers are also included considering that the task is to map HCI practice papers. The rationale for selecting studies published since 2000 is because the discourse on integrating HCI methods to software engineering processes began prominently around early 2000s (John, Kazman, Chen, \& Marcus, 2004; Ogunyemi \& Lamas, 2014) and it feels appropriate to conduct a search beginning at this period. Theoretical papers proposing a concept, technique or method that stems from empirical investigation(s) were also considered. We included only the most recent version of papers that reported the same study.

The criteria for excluding a paper are as follows:

- Studies not written in English; 
- Studies not directly linked to software development processes or projects;

- Studies based on tutorials, panel discussions;

- Short papers (<4 pages);

- Newsletters, magazine articles, personal blogs;

- Studies that are relevant but could not be accessed.

Table 5 is our screening process. A similar approach was used by Brhel et al. (2015). The screening process included five stages. We applied the inclusion and exclusion during each phase. There were some other papers that report on the use of HCI methods and had to be removed. In many cases, this set of papers either does not meet our requirement for page limit, or are not linked to software development processes or projects. There are some papers on software development that are not linked to HCI and also have to be excluded. Some of the papers that do not meet our page limit requirement are workshop and panel papers. In a few cases, some relevant papers were not accessible.

Table 5

Screening process for finding relevant papers (Adapted from Dybå and Dingsøyr 2008))

\begin{tabular}{lll}
\hline Phase & Process & Result \\
\hline I & Automatic search in digital libraries & 2384 \\
II a & Screen by paper titles & 340 \\
II b & Manual search in book of proceedings & 43 \\
III & Exclude duplicates & 332 \\
IV & Screen by paper abstracts & 167 \\
V & Screen by reading whole content of primary papers & 142 \\
\hline
\end{tabular}

We found 2384 papers automatically by searching digital libraries using the terms in Table 1. The results of the search are in Table 4. In the second phase, we screened the results of the automatic search by reading the papers' titles and reduced the list to 340 potentially relevant papers. Most of the articles found and discarded during this stage were editorials, panels, tutorials, special issues, and summaries. In addition to the second phase efforts, we manually searched proceedings of conferences such as Agile, INTERACT, CHI, HCII, NordiCHI, HCSE, ICSE, and found 43 relevant papers. Therefore, we added the 43 papers to the 340 potentially relevant papers and screened further by checking for duplicates. The list reduced to 332 potentially relevant papers after excluding duplicated papers. In the fourth phase we read the paper abstracts and eventually discarded 165 papers, bringing the number of potentially relevant papers to 167. In the fifth and final phase each paper was fully read and the finally included papers were reduced to 142 and analyzed further.

\subsection{Classification process}

The process described in Fig. 1 was followed in order to build the classification scheme of the primary studies. The rationale for identifying keywords from papers is to be able to build a valid classification scheme from the included primary studies (Petersen et al., 2008). We read the abstracts of the included papers and assigned keywords and concepts that clearly reveal the contribution of the articles. During this process, we also identified 
the context of each paper. We categorized the keywords and continued to update our schema. We refined the schema iteratively as we obtained new data. Eventually, we came up with the final classification schema. Furthermore, we used the schema to analyze the results presented in Section 5.

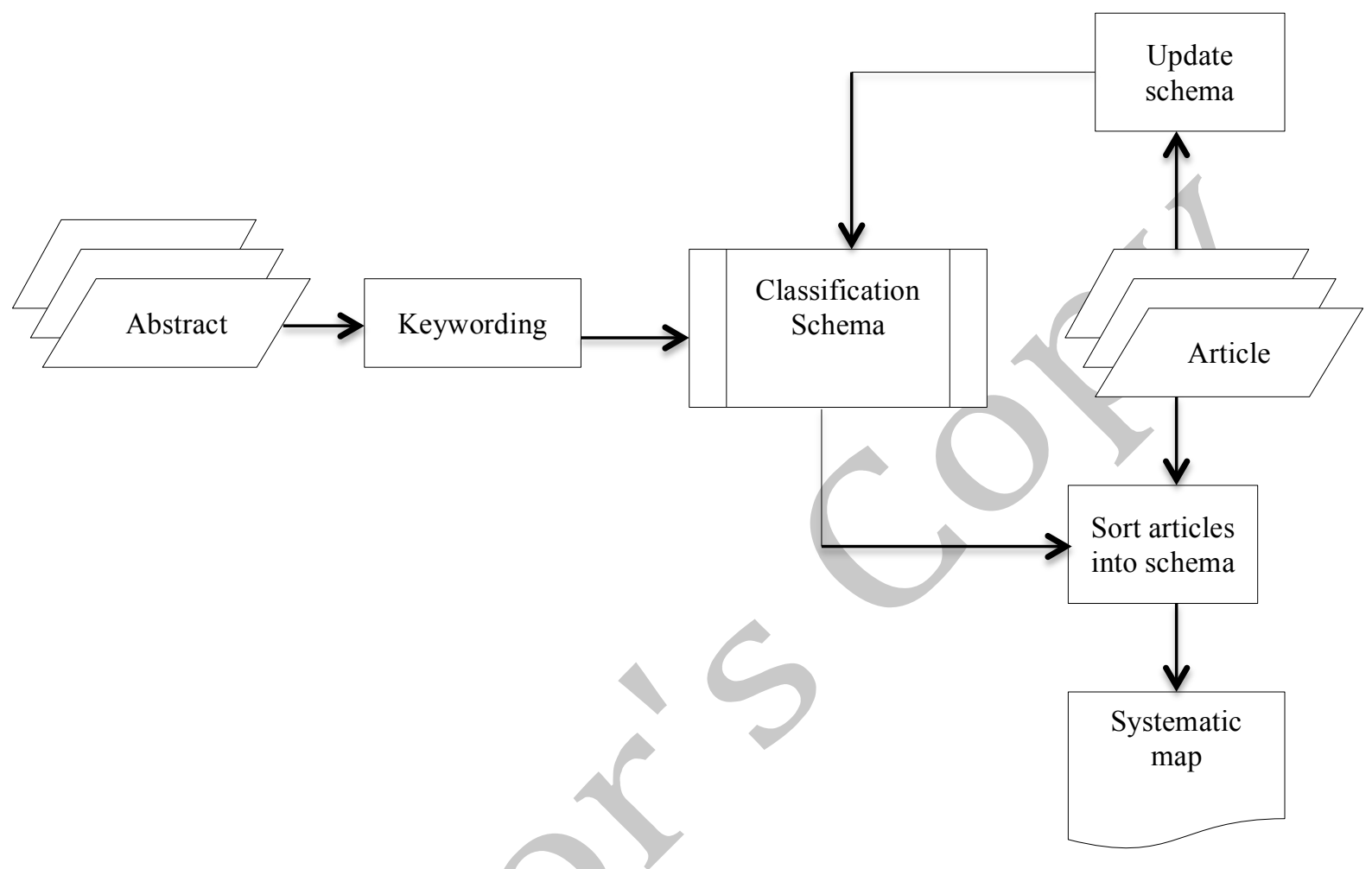

Fig. 1. Classification scheme building process (Adapted from Petersen et al. (2008)).

\subsection{Extraction of data}

We created a spreadsheet and extracted the following data, based on the classification scheme we have drawn, and following the methodology of similar studies such as ( $\mathrm{Da}$ Mota Silveira Neto et al., 2011; Paternoster et al., 2014; Wendler, 2012):

- Title of the paper;

- Publication year;

- Research methodology;

- Focus of the paper (in order to form themes of topics);

- HCI practice investigated;

- Software development lifecycle covered;

- Specific issue addressed in paper;

- Context (whether focused on projects or company process);

- Keywords. 
We read abstracts as well as the full papers being guided by the process we have defined for extracting data.

\subsection{Synthesis}

Data synthesis was done through automatic and manual processes. With automatic process, we used the MS Excel tool to collate data into a spreadsheet and thereafter perform some statistical analysis, which came up with relevant charts. In terms of the manual process, we performed the classification by topic ourselves by theming the keywords from the papers and categorizing them. Furthermore we repeated the process iteratively and refined and eventually arrived at the classification presented in this study.

\section{Classification scheme}

We followed the concept of keywording of abstracts described by Petersen et al. (2008). From the primary studies, we derived themes from the keywording process into topics as can be seen in Table 6 (a). Other aspects included in Table 6 are the classifications into research types (b), and contribution (c). Both classifications into research types and contributions were adapted as indicated in Table 6 (b), (c). The scheme presented in Table 6 is the basis for our systematic map presented in Figure 3.

Table 6

Classification scheme.

\begin{tabular}{|c|c|}
\hline Category & Descriptions \\
\hline \multicolumn{2}{|l|}{ (a) Topic Facet } \\
\hline $\begin{array}{l}\text { Design evaluation and } \\
\text { integration to software } \\
\text { processes }\end{array}$ & $\begin{array}{l}\text { Evaluation kinds and approaches to integration of HCI methods and } \\
\text { techniques to SE processes. }\end{array}$ \\
\hline Design methods and cont & $\begin{array}{l}\text { pplication of design methods in practice. Exploring the different } \\
\text { ays design methods are applied in contexts, effectiveness of design } \\
\text { chniques in use. Nature of practice and contexts in which teams } \\
\text { ork together. Approaches by which design methods could be } \\
\text { aproved. }\end{array}$ \\
\hline $\begin{array}{l}\text { Design innovations } \\
\text { Design-driven software } \\
\text { methodologies }\end{array}$ & $\begin{array}{l}\text { New ideas, concepts or ways for enhancing design and development } \\
\text { of interactive systems. } \\
\text { Integration of HCI methods and techniques to SW development } \\
\text { methodologies. }\end{array}$ \\
\hline Domain and knowledge & $\begin{array}{l}\text { Exploring how design work is being done when there is little or no } \\
\text { expertise required. Ways of mitigating shortage of skills in practice in } \\
\text { order to perform specific work tasks. }\end{array}$ \\
\hline Design tools and techniques & $\begin{array}{l}\text { New or existing tools and techniques for applying user research } \\
\text { methods. Tools for evaluating software usability. }\end{array}$ \\
\hline User research methods & Existing or proposed design methods for conducting user research. \\
\hline $\begin{array}{l}\text { Post-deployment activities and } \\
\text { software maintenance }\end{array}$ & $\begin{array}{l}\text { Feedback and other activities carried out after deployment of software } \\
\text { for use. }\end{array}$ \\
\hline $\begin{array}{l}\text { Design work and organizational } \\
\text { culture }\end{array}$ & $\begin{array}{l}\text { Pre-deployment or implementation activities and organizational issues } \\
\text { such as readiness. }\end{array}$ \\
\hline Cross-cultural design & Methods and techniques for collecting user data across cultures. \\
\hline Software process improvement & $\begin{array}{l}\text { Assessment of software processes using maturity models and allied } \\
\text { tools. }\end{array}$ \\
\hline
\end{tabular}




\begin{abstract}
Design-driven software architecture

Collaboration and team

communication

Exploring the interplay between design approaches and software architecture.

Exploring issues in, and ways of improving team communication and collaborations in organizations, or ways of enhancing end-user participation due to certain constraints such as illiteracy, disability or lack of willingness of the end-user.
\end{abstract}

(b) Research Facet (adapted from Wieringa, Maiden, Mead, and Rolland (2006))

Validation Research

Paper reports a study conducted in order to validate a proposed solution before its implementation in practice. Study uses relevant research methods such as experimentation, prototyping, modeling, simulation, etc.

Evaluation Research

Paper explicitly describes a problem in practice; study uses appropriate research methods to conduct the investigation. The paper builds on related studies and offers a significant contribution how the situation could be improved.

Solution Proposal Paper proposes new ideas, techniques, or methods and tries to just their relevance. The idea, techniques, or method might be novel or aims at improving the existing ones. In order to establish the relevance of the proposed solution, paper might include a description of a small-scale study.

Philosophical Papers $\quad$ Paper presents new approach of conducting investigation into a known phenomenon. The approach could be a conceptual framework, or model, etc.

Opinion Papers $\quad$ Paper expresses the personal opinion of the author about an issue, usually on what and why of such issue, or how things could be done.

Experience Papers Paper emanates from personal experience of the author. The paper enumerates lessons learned from the experience of the author, usually an industry practitioner, or a researcher who have used a tool. The report is without a description of research methods.

(c) Contribution Facet (adapted from Mujtaba, Petersen, Feldt, \& Mattsson (2008))

Process

Activities or actions and their corresponding work flow.

Tool Tools developed to support work activities, for example, software tools to support design activities.

Method Set of rules or ways things should be carried out.

Model

Connotation of real world using semantics and notations, representing something on a smaller scale, hypothetical description of a process, e.g. UML, simulation, maturity models, etc.

Metric Standards used for measurements.

\title{
5. Results
}

We present the results obtained from the analysis of the 142 primary studies.

\subsection{HCI paper distribution and venues}

The distribution of the 142 papers included is shown in Figure 2. It is understood that HCI practice research began to gain preeminence from 2003. During this period, deliberate efforts were made to bridge the gap between the HCI and software engineering fields. For example, a workshop was held in 2003 and the theme was "Closing the Gap: Software Engineering and Human-Computer Interaction" (Harning \& Vanderdonckt, 2003). The overarching concern at that time was to successfully integrate HCI methods into software engineering processes. As can be seen also in Figure 2B, majority of HCI practice papers have been shared through conferences. Precisely, 82 or $58 \%$ of the 
included papers were published in conference proceedings. There has been a steady increase in number of works produced on HCI practice from 2011. Apart from usability, which has been dominating the discourse, other issues that emerged include accessibility, user experience, and inclusiveness. These issues were found in papers such as SM112 published in 2009 and SM91 published in 2013 respectively. User experience is a dominating topic too as can be seen in many of the included papers. Since we stopped our search in July 2016, it is possible there could be more interesting papers produced from 2016 to date. This suggests there is a need for constant updating of mapping of HCI practice research papers.

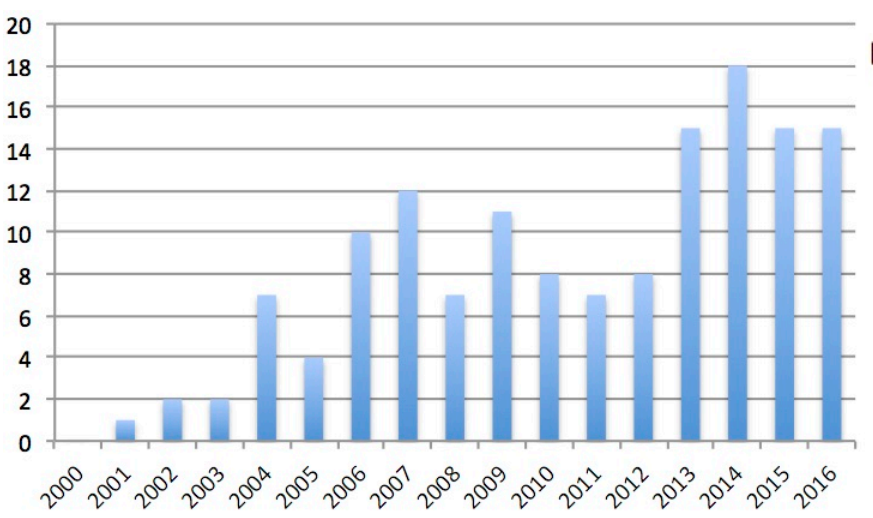

A. Publication year

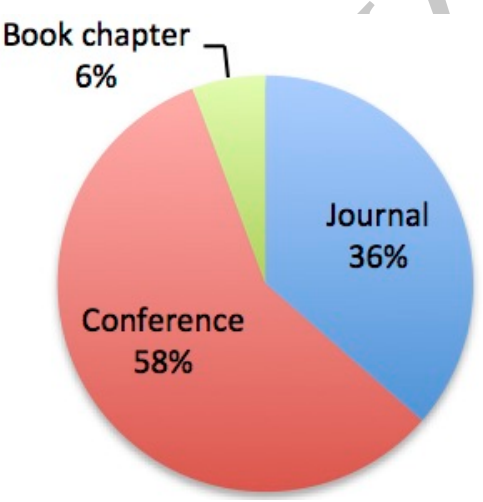

B. Venue

Fig. 2. Publication year and venue of primary papers

\subsection{HCI paper topic, evaluation, and contribution types}

Figure 3 is the overview of potential gaps in HCI practice research. We retrieved keywords describing the topic being addressed by each study as well as its type of research and contribution from a paper's abstract and author-defined keywords. Sometimes, we read the full paper if the contribution, research type and the topic being addressed cannot be well established and clear from the abstracts.

The systematic map is presented with three dimensional bubble charts on $x-y$ coordinates showing the areas of intersections (Petersen et al., 2008). The map shows an overview of the 142 primary studies we have chosen to be a representation of HCI practice. For example, in the dimension of topic, there are not many studies on post deployment activities and software maintenance ( 2 papers or $1 \%)$, cross-cultural design ( 2 papers or $1 \%$ ), and design-driven software architecture ( 3 papers or $2 \%$ ). However, 22 papers or $16 \%$ of the papers were on design work and organisational culture, design tools and techniques (25 papers or 18\%), design methods and contexts (24 papers or 17\%), collaboration and team communication (14 papers or 10\%), and software process improvement ( 5 papers or $4 \%$ ) and appear to be the dominating topics among the included papers. In particular, software process improvement has emerged to be a topic in the HCI practice domain since maturity models began to gain recognition in HCI practice research. Similarly, in the research type dimension, there are 11 papers on validation research (8\%), 10 philosophical papers (7\%), and 8 opinion papers $(6 \%)$ among others 
while the bulk of the papers are on evaluation research (73 papers or $51 \%$ ). In terms of contribution, there were 18 papers on tool (13\%), 16 papers on model (11\%) and just one paper on metric (1\%). The bulk of the papers were method-based (61 papers or $43 \%)$ and process-based (46 papers or $32 \%$ ).

In terms of mapping the results in Figure 3, it can be seen that almost all of the topics cut across different research types and offer different kinds of contributions. For example, collaboration and team communication as a topic was published as an experience paper, opinion paper, evaluation research paper, validation research paper, solution proposal paper and philosophical paper and at the same time offer contributions as tool, model, method, and process support. Thus, the topics appear not to be context-specific. 


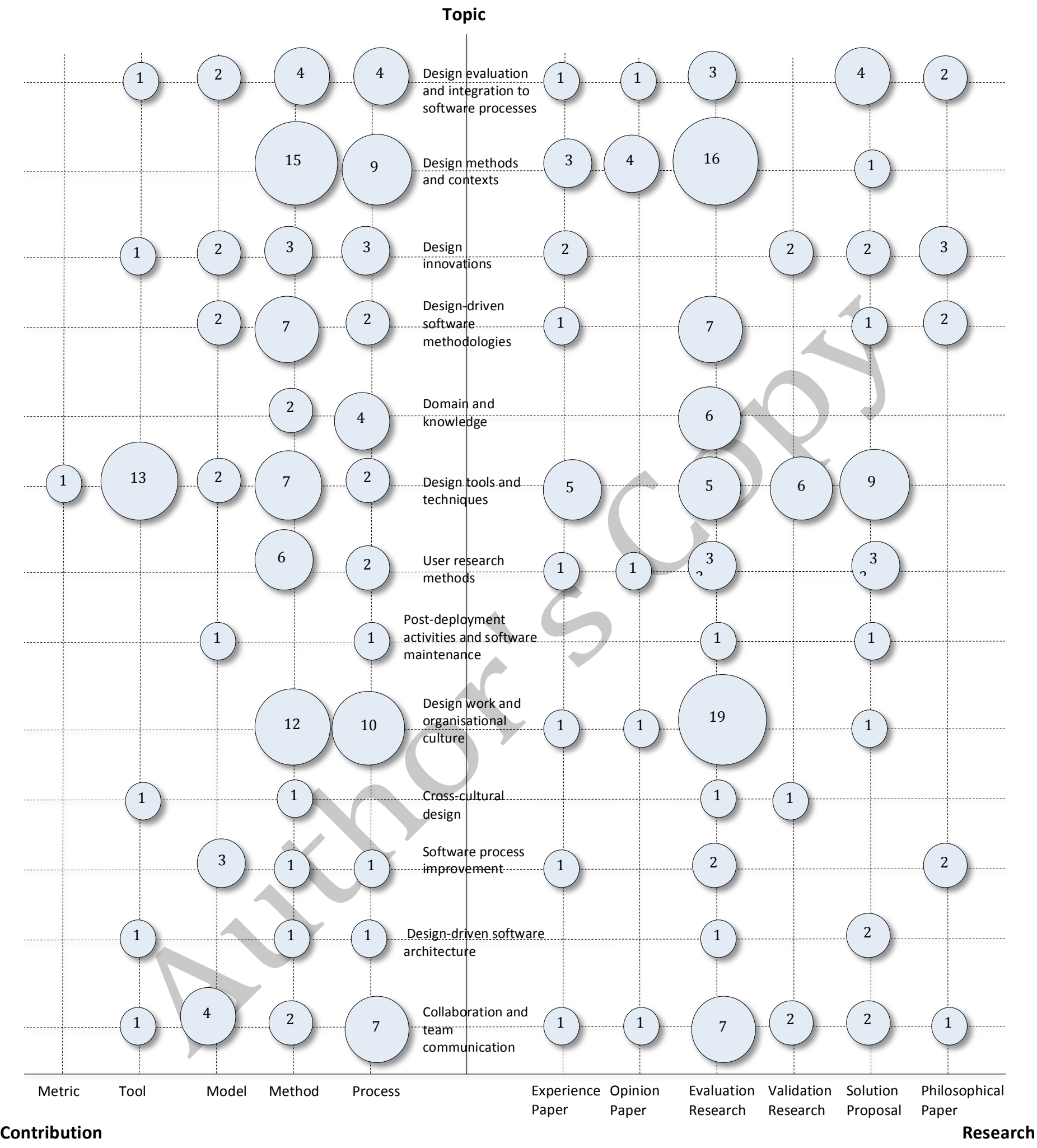

Fig. 3. Systematic map - Topic, research type, and contribution 


\subsection{Methods used to conduct HCI practice research}

The analysis with respect to RQ3 shows a variety of methods has been employed in conducting HCI practice research. One hundred and fourteen or $80 \%$ of the included articles were empirical and 28 papers were not empirical. These non-empirical papers include 6 experience papers, 8 opinion papers, 4 philosophical papers, and 10 solution proposal papers. However, there were 14 solution proposal papers that were empirical. These solution proposal papers employed a variety of methods such as experiment, case study, CMD, and survey among others. For example, SM04 (Kaasinen et al., 2015) proposed five approaches for acquiring insights for UX goal setting and conducted interviews in the context of an industrial system. SM08 proposed a method (Informal Cognitive Walkthrough) and conducted a laboratory experiment. Similarly, SM09 proposed a combination of two discount usability methods (RITE+Krug) and used the experiment method. SM11 while aiming to resolve the additional problems that arise after collecting user feedback when developing mobile applications proposed the CAFÉ (Context-Aware User Feedback) framework and was evaluated using experiment and interview methods.

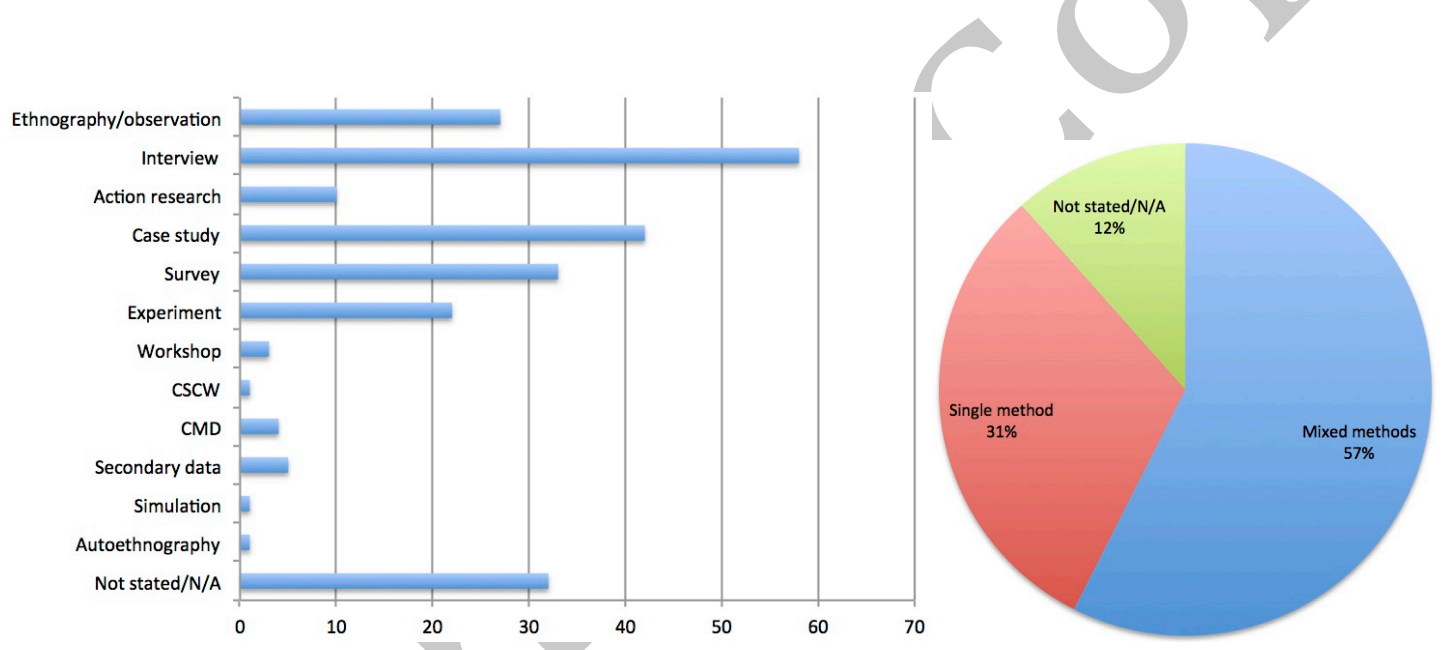

Fig. 4. (A) Research methods used in primary studies, (B) Proportion of methods used singularly to mixed methods

There were also 5 empirical philosophical papers and they used methods such as case study, survey, experiment, observation, and interview. For example, SM14 argue for software engineering to promote social change and describe a software development management framework that integrates action research, participatory design, and agile development to support the needs emanating from social software projects. SM14 carried out a social innovation case study. Figure 4 (A) shows that the interview method has been widely applied by almost half of the primary studies. Fifty-eight papers or $41 \%$ used the interview method. In Figure 4 (B), we can see that the proportion of studies that used combined methods (mixed) (57\%) is greater than those, which used singular methods $(31 \%)$.

\subsection{HCI techniques and context of use}

Figures $5(\mathrm{~A}-\mathrm{C})$ are indication of $\mathrm{HCI}$ techniques that were reported by the primary studies. The figures are divided into three phases and these were adapted from Bark et al. 
(2006). The phases are analysis and requirement, design, and evaluation. These phases are also described as the start, mid, and end phases.

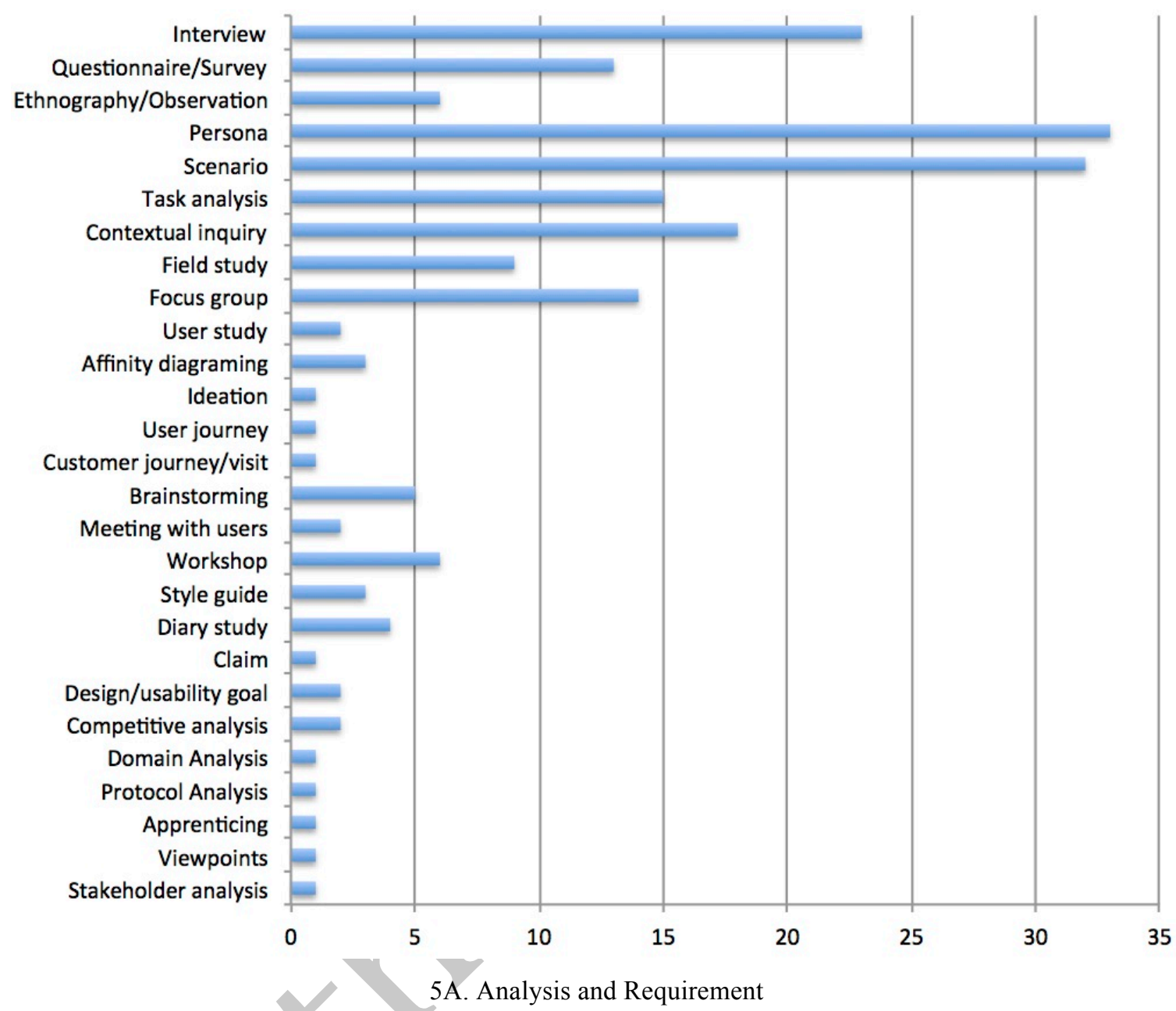

Start Phase. Figure 5(A) suggests that regarding the start phase of development projects, techniques such as persona (33 papers), scenario (32 papers), interview (23 papers), contextual inquiry (19 papers), task analysis (15 papers), and focus group (14 papers) are mostly used. For example, personas and scenarios have been applied in varying project contexts. In the study by SM02, personas were used in the context of a management system implementation. SM10 used personas in the context of a mobile application design and evaluation due to missing usability requirements. SM32 also describe the use of personas in the context of an in-house development project that integrates usability and health issues. SM44 used personas and scenarios techniques in the context of implementing a game development project for children and the motivation was to increase the overall user experience. There were techniques such as claims, competitive analysis, domain analysis, and viewpoints that are interesting but not commonly reported unlike persona, scenario, interview, and contextual inquiry. For example, claims have been defined as a "means of expressing HCI knowledge that is associated with a specific artifact and usage context" (Sutcliffe \& Carroll, 1999, p. 213). According to Sutcliffe and Carroll (1999) claims are "created in the task-artifact cycle of interactive design and 
evaluation" (p.213). Techniques such as contextual inquiry and interview might be similar as both tend to be used to elicit certain knowledge or information directly from stakeholders such as users. Contextual inquiry and field study are also similar in the way that both are conducted in the context of the user.

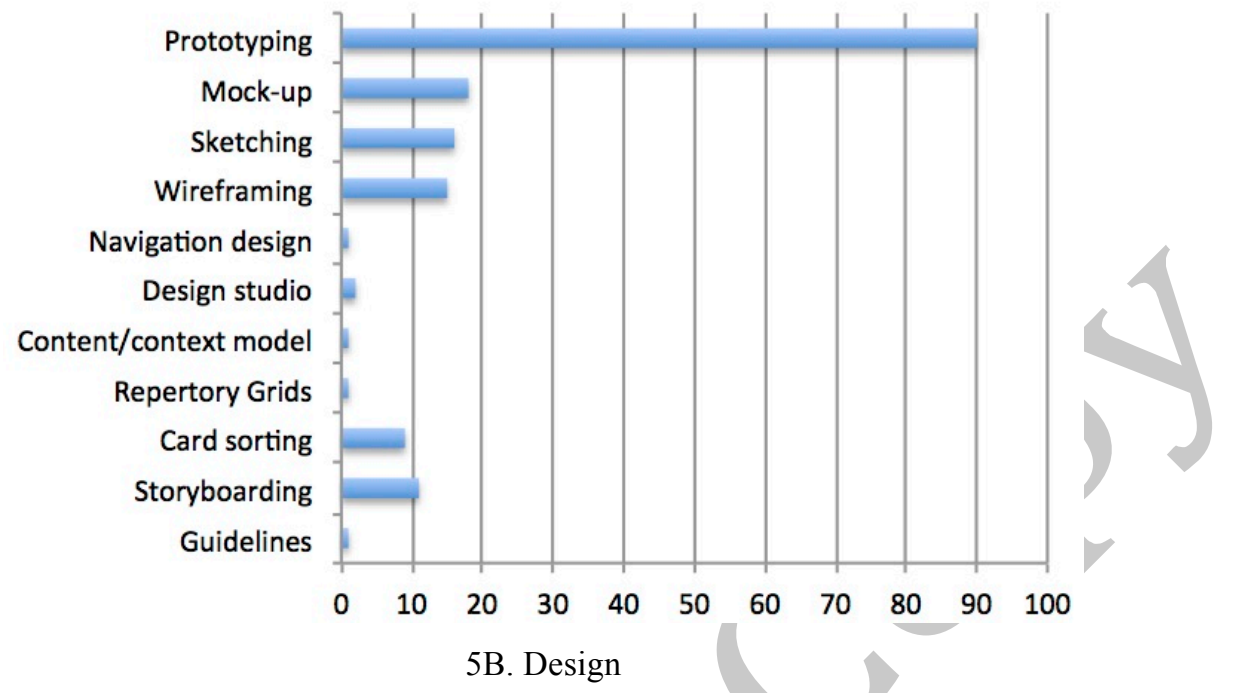

Mid-Phase. Regarding the mid phase, it appears that prototyping (90 papers), sketching (16 papers), mock-up (18 papers), wireframing (15 papers), and storyboarding (11 papers) techniques are mostly used in designing software. The results are shown in Figure 5(B). These techniques have also been used in different development contexts. For example prototyping has been used in the contexts of designing game development software (SM44, SM96, SM100), mobile application (SM45, SM51, SM56, SM65, SM68, SM88, SM89, SM124, SM131), web application (SM50, SM60, SM69, SM80, SM88, SM89, SM107, SM112, SM132), information systems, SM70), educational software (SM91), ambient intelligence system (SM120), and generally product development (e.g. SM48, SM59, SM64, SM66, SM82, SM83, SM93, SM108, and SM116). Meanwhile wireframes and mock-ups are some forms of low fidelity prototypes.

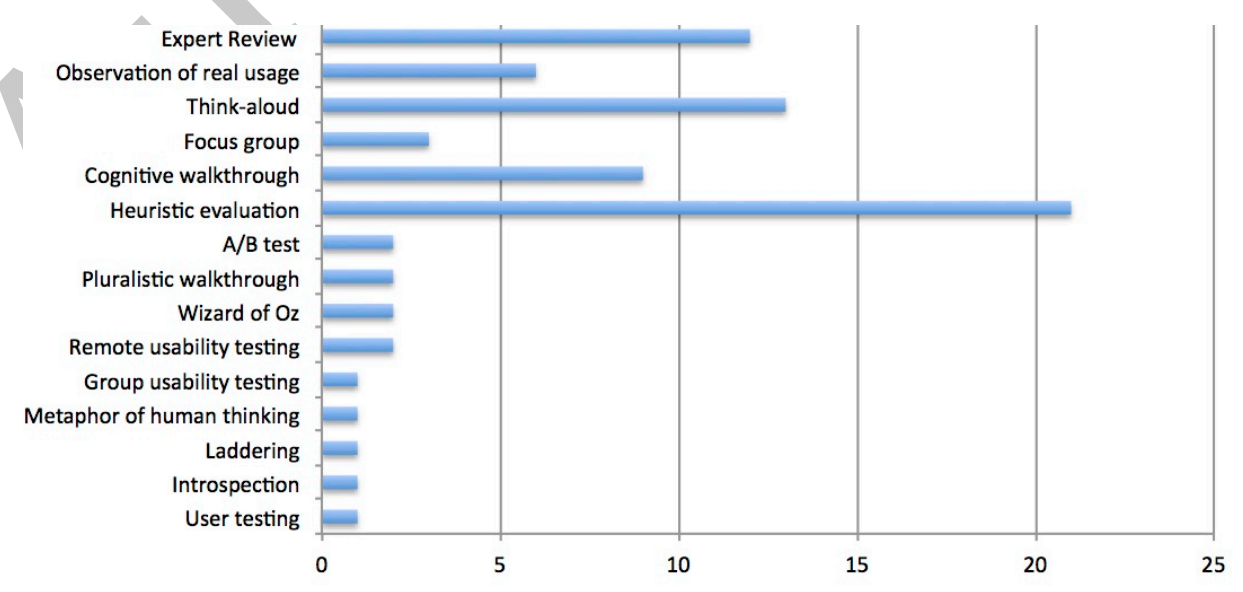

5C. Evaluation 
Fig. 5. HCI Techniques found in studies

End-Phase. Regarding the end phase, it appears that heuristic evaluation (21 papers), think aloud (13 papers), expert review (12 papers), and cognitive walkthrough ( 9 papers) techniques are mostly used in software projects evaluation. It can be noted that heuristic evaluation, cognitive walkthrough and expert review are all review-based methods that don't involve users. The major difference between cognitive walkthrough and pluralistic walkthrough is that unlike the former the latter brings together representative users, the system designers, and a usability expert for the walkthrough session.

\subsection{HCI practice research application areas - (Development Areas)}

The results in Figure 6 indicate that HCI practice has been widely applied. The mostly applied area is in product development. As can be seen in Figure 6, there are 67 papers on product developments. The results, however, do not suggest tying particular HCI techniques to particular areas of applying HCI practice. Rather the results only give an insight that HCI practice is being conducted in several development domains. Furthermore, some papers are not about developing a specific product, but meta-papers such as survey studies. As an illustration, there were 90 papers (Figure 5B) that reported the use of prototyping techniques and of this, 40 papers are on product development. Similarly, other studies that reported the use of prototyping include 14 papers on web application, 11 papers on mobile application, 1 paper on ambient intelligent system, 4 papers on game development, 1 paper on educational software, 1 paper on assistive technologies, 8 papers on diverse development, 7 papers on information/management systems, 2 papers on in-house development, and 1 paper on industrial system development.

Product development is more or less associated with commercial products and many of the studies indicate differing areas regarding HCI practice in product development. For example, SM27 examined usability capability maturity assessment of a product development organization. SM29 argued that user involvement is interwoven with organisational culture in product development and suggests cultural analysis of product development organisations. SM39 explored the role of usability maturity models in integration of UCD and agile processes. Similarly SM41 examined the state of integration of usability/UCD to agile methods. SM93 and SM94 reported how their organisations adapted to Agile UX/UCD. In particular, SM93 reveal moving from waterfall to Agile UCD was a learning curve for their organisation. Similarly, SM98 described 5 myths associated with Agile UX practice in product development organisations. The myths are: (1) there is only one way to "do" Agile UX; (2) one cannot conduct user research; (3) no "upfront" design is permitted; (4) UX deliverables or documentation should NOT be created (or MUST be created); and (5) one doesn't need to have any agile training. SM99 shared how UX practice is being conducted at Google. The paper indicates that a focus on user is crucial for the success of a product development organisation. SM48 reveals that users responsibilities in SCRUM projects are not clear, and SM55 describes how usability evaluation was integrated into a SCRUM projects using a technique known as Remote Synchronous User Testing (RS).

Diverse development means that more than three kinds of development were looked at. These studies were majorly by survey and interview methods. For example, SM06, and SM87 investigated adoption of HCI practice in software development companies in two 
different countries. Similarly, SM79 using interviews method, investigated adoption of UCD methods in smaller Eastern Finland IT companies. SM73 and SM78 used the survey method to investigate work practice regarding which methods HCI practitioners find most useful in projects and post-deployment usability issue respectively. SM05 used the survey method to investigate process adaptation regarding fitness of UX to scrum/kanban. All these studies indicate the companies were into diverse developments.

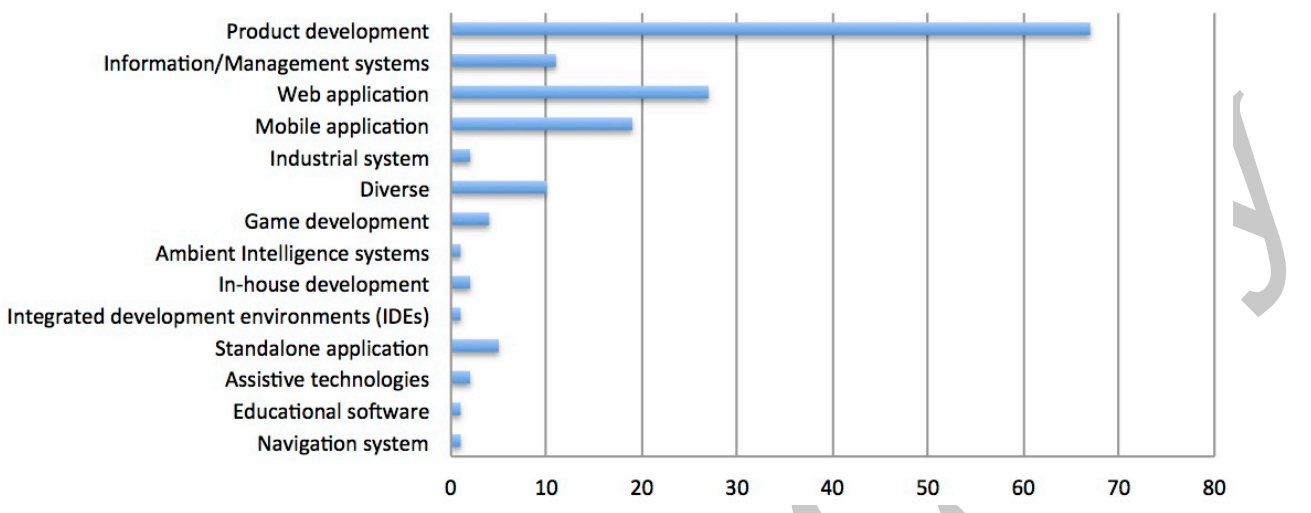

Fig. 6. Areas of HCI Practice application

Several issues relating to web application development were also addressed. For example, SM03 investigated adoption of UCD and usability among 184 Korean IT practitioners and 90 user interface/usability practitioners and the companies were into web and mobile developments. Similarly, SM13 investigated user feedback incorporation into web application development. SM25, SM33, SM60, and SM76 investigated work practices of usability evaluation in web application, usability engineering support tool for online photo album application, use of HCI knowledge in web application development, and usability and redesign in web application development respectively. SM40 and SM77 investigated integration of UCD principles such as user involvement, rapid prototyping, and continuous testing and effectiveness of usability evaluation methods respectively. SM35 and SM63 examined usability requirements issues such as the link between usability requirements and software architecture, and methods and guidelines to direct users in eliciting usability requirements respectively in the context of web application development. SM69 examined stakeholders' collaboration regarding use of diary study technique to explore the design process of complex engineering systems also in the context of web application development. Other areas of applying HCI practice include game development (SM15, SM44, and SM100), ambient intelligence systems (SM118), assistive technologies (SM90, SM112), and educational software (SM91). SM34 examined integration of usability work into industrial systems projects.

\subsection{Challenges of HCI practices in software development companies}

We classified the challenges reported by many of the selected studies reviewed into four challenges, namely: performance of projects, expertise, methods, and process. By performance of projects, we mean the actual conduct of usability/UX design, that is those tasks that teams should carry out. Expertise refers to the professionals that carry out project tasks. Methods are HCI principles for conducting work practices. Finally, process is defined as methodological procedures for organizations based on standard design 
practices. Table 7 shows the challenges reported. The majority of the problems reported are tied to process, followed by performance of projects and expertise.

\section{Table 7.}

Challenges of conducting HCI practices in development companies

\begin{tabular}{|c|c|c|c|}
\hline $\begin{array}{l}\text { Performance of } \\
\text { projects }\end{array}$ & Expertise & Method & Process \\
\hline $\begin{array}{l}\text { Quantitative evaluation } \\
\text { (SM01) }\end{array}$ & $\begin{array}{l}\text { UCD Knowledge } \\
\text { (SM02, SM03, SM33, } \\
\text { SM42, SM53) }\end{array}$ & $\begin{array}{l}\text { Practical } \\
\text { usability/UCD } \\
\text { methods (SM03, } \\
\text { SM107) }\end{array}$ & $\begin{array}{l}\text { Development cost and time } \\
\text { (SM03, SM59, SM71, SM80) }\end{array}$ \\
\hline $\begin{array}{l}\text { Heterogeneity of users } \\
\text { (SM10) }\end{array}$ & $\begin{array}{l}\text { Trained HCI experts } \\
\text { (SM03, SM06, SM10, } \\
\text { SM21, SM71, SM86, } \\
\text { SM116, SM117, } \\
\text { SM132) }\end{array}$ & $\begin{array}{l}\text { Fit for small } \\
\text { companies } \\
\text { (SM06) }\end{array}$ & $\begin{array}{l}\text { Distinction between customers } \\
\text { and users (SM05, SM06) }\end{array}$ \\
\hline $\begin{array}{l}\text { Usability is fuzzy } \\
\text { (SM22, SM31) }\end{array}$ & $\begin{array}{l}\text { Tacit knowledge } \\
\text { (SM06) }\end{array}$ & $\begin{array}{l}\text { Integration } \\
\text { (SM43, SM45, } \\
\text { SM46, SM47, } \\
\text { SM75, SM80, } \\
\text { SM86, SM121) }\end{array}$ & $\begin{array}{l}\text { Management support (SM09, } \\
\text { SM21, SM23, SM31, SM32) }\end{array}$ \\
\hline Project vision (SM70) & $\begin{array}{l}\text { Awareness of usability } \\
\text { methods (SM10, SM31) }\end{array}$ & & $\begin{array}{l}\text { Organizational culture (SM29, } \\
\text { SM32, SM80, SM86, SM97) }\end{array}$ \\
\hline $\begin{array}{l}\text { Agile UX (SM70, } \\
\text { SM91, SM94, SM103) }\end{array}$ & $\begin{array}{l}\text { Usability engineering } \\
\text { tool (SM33) }\end{array}$ & & $\begin{array}{l}\text { Difficult to control architecture } \\
\text { process like RUP (SM31) }\end{array}$ \\
\hline $\begin{array}{l}\text { Software } \\
\text { documentation (SM71, } \\
\text { SM137) }\end{array}$ & $\begin{array}{l}\text { Knowledge of HCI } \\
\text { concepts/techniques } \\
\text { (SM37, SM105) }\end{array}$ & & $\begin{array}{l}\text { Software architecture/design } \\
\text { usability (SM107, SM111, } \\
\text { SM113, SM120, SM124) }\end{array}$ \\
\hline \multirow[t]{3}{*}{$\begin{array}{l}\text { User involvement } \\
\text { (SM99, SM111, } \\
\text { SM115, SM118) } \\
\\
\text { Late start of UX } \\
\text { activities/UX design } \\
\text { (SM82, SM123, } \\
\text { SM128, SM129, } \\
\text { SM130, SM131) }\end{array}$} & $\begin{array}{l}\text { Usability evaluation } \\
\text { (SM100, SM101, } \\
\text { SM104, SM108, }\end{array}$ & & $\begin{array}{l}\text { Communication in } \\
\text { projects/Stakeholders' } \\
\text { collaboration (SM13, SM17, } \\
\text { SM23, SM31, SM38, SM57, } \\
\text { SM65, SM70, SM71, SM82, } \\
\text { SM117, SM 127, SM 134, } \\
\text { SM139, SM140) } \\
\text { Customer's } \\
\text { awareness/participation (SM31, } \\
\text { SM80, SM135) }\end{array}$ \\
\hline & & & $\begin{array}{l}\text { Eliciting requirements (SM21, } \\
\text { SM51, SM68, SM106, SM136) }\end{array}$ \\
\hline & & & $\begin{array}{l}\text { Usability requirements (SM10, } \\
\text { SM35, SM36, SM63, SM67, } \\
\text { SM113, SM114, SM126, } \\
\text { SM129) } \\
\text { Training (SM59) } \\
\text { Leadership (SM81) } \\
\text { Incorporating user feedback } \\
\text { (SM01, SM10, SM11, SM12, }\end{array}$ \\
\hline
\end{tabular}


The challenges regarding process are from organizational culture to team communication through to the stakeholders involved in the process. For example, it is reported there is lack of vision due to lack of management support. The roles of users and customers are obscure because there is a lack of clarity regarding who stakeholders are, and what roles they are expected to play? There is poor communication between developers and designers before and during projects. SM09, SM21, SM23, SM31, and SM32 reveal HCI practice is being challenged by lack of management's support. Two studies (SM03, SM108) identified lack of practical usability and UCD methods to support HCI professionals. However, SM09 while admitting the challenge of lack of management's support believe discount usability methods to meet demands of time and resources for usability can help UX professionals cope better. In general, the overarching challenges regarding development process are in terms of software architecture/design usability, communication in large projects, missing usability requirements, and incorporating user feedback.

Nine studies (SM03, SM06, SM10, SM21, SM71, SM86, SM116, SM117, SM132) report there is a challenge of trained HCI experts and although there are few experts; there is still a challenge of lack of HCI knowledge. For this reason, SM21 offered six recommendations for improved usability work in R\&D organizations through prioritizing and educating HCI professionals to conduct usability work. There are also few cases of lack of usability engineering and knowledge management tools.

There are some challenges with $\mathrm{HCI}$ methods such as their suitability for small companies, adaptability, and integration to software methodologies. For example, humancentred design is not fit for small companies because of lack of resources. Usability is said to be fuzzy during projects and users tend to be heterogeneous. The major challenge regarding performance of projects appear to be late start of UX activities or UX design as a whole.

\section{Discussion}

Research in the domain of HCI practice in relation to software engineering has emerged and continues to grow. We present detailed discussions of the results in this section.

6.1. RQ1 - How are HCI practice papers distributed over the years and in what venues? The results presented in Table 4 show that HCI/SE research papers could be found in multiple sources. However, the results also indicate the prominent digital libraries are:

- Springer;

- ScienceDirect;

- ACM;

- Taylor and Francis, and;

- IEEE Xplore. 
These sources include many conference and journal papers. Springer is particularly known for publishing digitized books. Springer among other conference proceedings publishes the following proceedings:

- International Conference on Process Improvement and Capability dEtermination in Software, Systems Engineering and Service Management (SPICE);

- International Conference on Human-Computer Interaction (INTERACT), and;

- International Conference on Human-Centered Software Engineering (HCSE).

ScienceDirect publishes many top journals such as:

- Information and Software Technology;

- Journal of Systems and Software, and;

- International Journal of Human-Computer Studies.

ACM publishes many top conferences in the field of HCI such as:

- Conference on Human Factors in Computing Systems (CHI), and;

- Nordic Conference on Human-Computer Interaction (NordiCHI).

ACM as well publishes conference proceedings in the field of SE such as:

- International Conference on Software Engineering (ICSE), and;

- Human Aspects of Software Engineering (HAoSE).

In addition to this, ACM also archives journals papers in $\mathrm{HCI} / \mathrm{SE}$ such as the Journal of Usability Studies.

Taylor and Francis publish HCI journals such as:

- International Journal of Human-Computer Interaction, and;

- Human-Computer Interaction.

IEEE publishes conference proceedings of:

- Cooperative and Human Aspects of Software Engineering (CHASE);

- Design and Innovation in Software Engineering (DISE), and;

- Agile Conference (AGILE).

These avenues discuss issues relating to $\mathrm{HCI}$ and $\mathrm{SE}$ among other issues. Publications are also found in other sources such as IEEE. As can be seen in Figure 2B, there is a higher proportion of conference papers to that of journal papers. Conferences are good avenues for discussing late breaking results and journals and books are excellent for archiving well-established results. Our findings in this study show that 71 papers accounting for $50 \%$ of the 142 primary studies were published between 2012 and as at the time of concluding the search in July 2016 ( 5 years). Furthermore, of the 142 papers, 110 papers were from the academia, while 32 papers were from the industry. Of the 142 papers, there are 10 papers co-written by researchers from academia and industry practitioners based on industry/academia research collaboration. These trends are promising given that many software development companies are recognizing the importance of user consideration in software development processes (Hess, Randall, Pipek, \& Wulf, 2013; Rogayah Abd Majid, Noor, Adnan, \& Mansor, 2009). 


\subsection{RQ2 - What types of papers are published in the topic areas and what type of evaluation and contribution do they offer?}

By our classification, HCI practice research topics are centralized on design tools and techniques (25 papers), design methods and contexts (24 papers), design work and organizational culture (22 papers), and collaboration and team communication (14 papers). These topics account for 85 (or 60\%) of the 142 primary papers reviewed. Possibly, these topics could be perceived as prevailing topics in HCI practice research with relation to $\mathrm{SE}$ processes. However, topics such as Design-driven software architecture (3 papers), Post-deployment activities and software maintenance (2 papers), and cross-cultural design ( 2 papers) have not received extensive HCI practice research attention. These topics are considered very important especially with increasing effort in Agile UCD integration, and HCI across borders. Cross-cultural design was particularly indicated by SM015 as an area that requires more research focus in order to respond demands being created by emerging markets. Agile approach to elicit user data in order to assist designers to innovate with products and services that do not undermine the cultural issues within the emerging markets was in particular pointed at. For this reason, SM141 proposed a tool for analyzing cross-cultural requirements for designing navigation systems. These topics could be interesting to future researchers. SM077 argued that it is imperative to conduct usability maintenance, that is, understand what happens to the usability of a system after its deployment. The vast majority of the topics are centered on usability engineering, user experience design, and UCD issues.

Our classification scheme has been presented in Table 6. Our own effort was to build a topic facet, which categorizes the primary studies. We have adapted the other two facets as rightly described in Table 6 . Evaluation research papers ( 71 papers or $50 \%$ of the total) as can be seen in the systematic map presented in Figure 3, is the largest proportion of the primary studies. This is not surprising because the field of HCI is primarily concerned with the design, evaluation, and implementation of interactive computing systems for human use and with the study of major phenomena surrounding them (Hewett et al., 1996). Figure 3 also revealed that 'Solution proposal' (informed by 26 papers) is the second largest in the proportion of research type. Our findings in terms of the proportions of evaluation research and solution proposal are similar to the findings of Mujtaba et al. (2008), which looked at software product line variability. However, there are very few papers in the category of opinion papers (8 papers), validation research (11 papers) and philosophical papers (10 papers). In view of the relative low proportion of these categories of papers, there is a need for more contributions as regard these types of research. For example, validation research could be a follow up effort to a proposed solution, which has yet to be implemented in practice (Wieringa et al., 2006). Philosophical research offers conceptual understanding of issues (Mujtaba et al., 2008). A major concern with the proportion of solution proposal papers to validation papers is that there is a risk of proliferating things. The shortage in conducting validation research could in a way limit the process of transferring research results to practice. This view is corroborated in the study by Wieringa et al. (2006), which note that "validation is weak in software engineering papers" and same could be passed for related disciplines such as HCI. New solutions should be validated within industrial contexts in order to strengthen their rate of adoption in practice. In terms of contribution, method (evident by 61 papers or $43 \%$ of the total) is topmost, followed by process (46 papers or $32 \%$ of the total). 
There is however, just one paper that contributed to metrics. Eighteen papers contribute to tool and 16 papers to model for supporting software engineering works.

If we therefore, map the three dimensions we see that evaluation research is dominant in HCI practice research and topics such as design tools and techniques, design methods and contexts, design work and organizational culture, and collaboration and team communication are prevalent. The majority of these also contribute to methods and processes of software engineering in relation to HCI.

\subsection{RQ3 - What research methods have been mostly applied in HCI practice researches?}

It can be seen from the results presented in Figure 4 (A, \& B) that the interview method appears to be predominant in HCI practice research. Case study and survey methods are also widely used. However, other relevant methods such as action research, ethnography, and CMD are not as widely used. It has been argued that in order to improve the state-ofart HCI practice research, sometimes as researchers, we need to work from within companies (Ardito et al., 2014; Kotzé, 2002). Action research is suitable for uncovering salient issues in practice and for understanding practitioners' needs and challenges (Gulliksen, Cajander, Sandblad, Eriksson, \& Kavathatzopoulos, 2009; Hayes, 2014). Cooperative Method Development is a sub-set of action research and a method of inquiry with practitioners in which researchers and practitioners cooperate to investigate a phenomenon and implement their findings through empirical research (Ardito et al., 2014). As HCI approaches have yet to be adequately addressed in practice, we argue that future researchers could look closely into these underutilized research methods. It is however, interesting to see that researchers used mixed methods in higher proportion when compared to use as single methods of inquiry. Mixed methods research is particularly relevant when aiming to deal with complex issues (Johnson \& Onwuegbuzie, 2004). However, relative to software methodologies, it appears there is a growing interest in agile methodologies such as SCRUM, and Extreme Programming (XP). The reason could be due to pressing need for rapid deployments, tight budgets and project deadlines (Memmel, Gundelsweiler, \& Reiterer, 2007).

\subsection{RQ4 - What HCI techniques have been reported in the current literature regarding $\mathrm{HCI}$ practice and in what context of use?}

The results indicated by Figures 5(A-C) suggest that HCI techniques are increasing in adoption in software development companies as well as in projects. The start phase included planning, analysis, and requirement, while the end phase relates to evaluation. In the start phase, techniques such as persona, scenario, interview, contextual inquiry, focus group and survey are being predominantly used. Prototyping appears to be the predominantly used technique in the mid phase, while heuristic evaluation, think aloud, expert review, and cognitive walkthrough are used techniques in the end phase.

From the reviewed papers, it was found that the use of the afore-mentioned techniques has also been largely promoted by the introduction of ISO standards for human-centred developments such as ISO 13407 (ISO, 1999), which was later developed into ISO 9241210 (ISO, 2010). ISO 9241-210 is a framework, which specifies 6 principles for humancentred development. The 6 principles are:

i. Explicit understanding of users, tasks, and environments; 
ii. Involvement of users throughout design and development phases;

iii. Design of the system is driven and refined by user-centred evaluation;

iv. Design of the system is iterative;

v. Design of the system addresses whole user experience, and;

vi. Multidisciplinary skills and perspectives are applied to the design process.

Researchers found iterative design as a strong commonality between the human-centred design principles and agile principles. Therefore, there have been several efforts to integrate human-centred design and agile methodologies. SM91 advocated for Agile UXD for inclusive educational software design where they argued that UCD puts the user at the heart of design contrary to agile methodologies, which put the developer and the customer at the center. In particular, the authors noted that UCD describes "a prototypedriven software development process, where the user is integrated during the design and development process" (p.150). A similar remark was made by SM96 for serious game development, SM131 for UX development for collaborative mobile prototyping and SM43 for integrating UCD to agile processes. Nevertheless SM115 outlines 4 challenges found with implementing UCD, namely: (1) Acceptance, recognition and incorporation of the User-Centred Design practice, (2) Lack of resources, (3) Changes in the projects definition, and (4) Management of multidisciplinary team. Similarly, SM30 while exploring familiarity of usability methods among map application developers argued that it is not always straightforward to integrate methods emanating from different research domains to other application areas. One reason presented by the authors is lack of knowledge required for integration. SM79 found that adoption of UCD methods is low in smaller companies in Eastern Finland. SM88 found that the impact of the professionalclient relationship is a key factor that hinders user involvement in the context of designing mobile systems by UCD practitioners.

Other records of applying HCI techniques include the work of SM111, which explored optimization of persona and scenario in the design and evaluation of usability and accessibility of Ambient Assisted Living (AAL) systems and services. Personas and scenarios were found beneficial to addressing the difficulty of communication experienced among stakeholders (users, care givers, developers) involved in the development of AAL systems and services. However, SM62 found that in practice, personas might not be used as described in the literature; rather practitioners create personas based on the real users and only employ the technique when they feel comfortable to do so. The rationale for creating personas based on the real users is that if the wrong user group is described in personas it could lead to developing wrong software solutions. This finding could be interesting for future researchers. The study also revealed that practitioners perceive scenarios relevant based on its similarity with user stories. Personas have also been proposed as a conjoined technique that could be used with Generic User Experience Model (MEX) Experience Boards to uncover hidden UX issues by SM103. Similarly, SM105 in their study modified personas into a technique that can be used to elicit software requirements. SM124 shared their experience of integrating personas into Extreme Programming/UCD process. According to this study, personas were created in two stages; in the initial stage based on existing user studies and in later stage based on new studies. Personas had to be iteratively refactored due to visible changes emanating from the new studies. Therefore, it was concluded in the study that 
personas should be well introduced to the team to foster planning and development of the solution and decision-making process.

SM75 in a survey of practitioners' adoption of UCD found that user interview and prototyping (low and high fidelity) were the mostly used techniques. SM91 found that prototyping and heuristic evaluation were useful, fast, and efficient techniques in the design and evaluation of inclusive education software for children with certain learning difficulty. Similarly, SM100 found prototyping as a useful technique in early pervasive game development. Paper prototyping when used to create detailed screen layouts, and software prototyping techniques were found to be effective but time-consuming. The reasons for time-consumption are complexity of game application and detailed prototyping. Nevertheless, early prototyping was found valuable. SM93 reported that prototyping, and usability testing, were adopted by a company moving from waterfall process to Agile UCD. Lightweight prototyping were used in the study by SM124. SM125 in harnessing the benefit of prototyping technique, proposed POLVO software that has the functionalities to create low-fidelity prototypes, document, and support user testing to facilitate interface development in SCRUM process. SM131 developed a mobile prototyping tool (Prime) to facilitate elicitation of hedonic issues in user requirements by focusing users' tasks in context of use. From the foregoing, we can understand that HCI techniques have varying benefits and the known challenges should be looked into.

\subsection{RQ5 - In what development project areas has HCI practice been applied as documented in the existing literature?}

As can be seen in Figure 6 HCI practice cuts across a wide variety of interactive systems development. The analysis of the results reveals that similar issues are associated with the different areas or development focuses where HCI practices are being applied. The common areas where HCI practices are being conducted include product development, especially commercial software, web application, mobile application, information/management systems, and game development. Others include industrial systems, educational software, and assistive technologies. It can be understood that advances in web and mobile technologies might be responsible for companies to conduct HCI practices. However, SM35, and SM112 stressed that web application developments are complex systems. For example, SM35 examined the impact of usability on web systems. In particular, the study investigated the link between usability requirements and software architecture by examining five scenarios in which usability problems can be found. The study found that supporting international use has a major usability impact on web application architecture. Other results include checking for correctness (intermediate impact), providing good help (minor impact), modifying interfaces (minor impact), while retrieving forgotten passwords has no usability impact on web application architecture. Regarding interfaces, SM60 argued that many web application interfaces are still difficult and annoying to use. Frustration usually arises from inefficiency of web application. In the same vein, SM112 noted that usability requirements are often missing in quality requirements of web applications and proposed a requirement metamodel for eliciting requirements in web application projects such as web information systems. The metamodel seeks to capture usability issues by conducting early usability evaluation. 
Mobile application development is said to have a unique challenge of short time to market according to SM74. For this reason, the authors explored use of usability techniques and the effect of such endeavor on user interface design of a mobile application development project. The study reported the useful benefits of conducting usability testing during the project. SM131 developed a mobile prototyping tool to aid users' tasks in their context of use. Particular focus of the tool is on revealing hedonic parameters in design process through mobile prototyping.

SM91 described an education software development project in which inclusiveness of the software was prioritized in the design process. The software was intended for children with Downs's syndrome - a learning difficulty. The goal was to identify usability problems and UX factors in the early stages of developing educational software for users with special educational needs. Similarly, SM90 stressed end users engagement in assistive technologies development is a major challenge. This is especially found true of people with severe disabilities such as adults with Severe Speech and Physical Impairments (SSPI). In particular their involvement in projects is problematic. A solution adopted by the study was the inclusion of user advocates in agile UCD process. Overall, it can be concluded that areas of applying HCI practices in development projects is inexhaustible. It depends on the project at hand and whether the intention is to build interactive systems for specified users and in specified contexts of use.

\subsection{RQ6 - What challenges have been reported in software development companies regarding $\mathrm{HCI}$ practices?}

Focusing on the challenges presented in Table 7, one could see the overarching issues are personalities involved with development processes. User feedback incorporation is one of the main usability evaluation issues in companies. It would be recalled that one of the principles of human-centred design is design driven by user-centred evaluation. This implies that a lot of feedback can be collected from users and other stakeholders during the design process. Therefore, in attempting to integrate UCD to agile processes, challenges arise due to rapid communication with different stakeholders to elicit feedback and implement feedback within design iterations. For example, it could be overwhelming for the project team to determine at what point should enough feedback have been elicited and whether all feedback should be incorporated. Feedback from user is mostly based on usability and user experience of using the system. For example, SM01 hinted that it is challenging to incorporate user feedback in Scrum process due to rapid releases of working software and exquisite stakeholders' communication. Informal feedback are managed to be collected from very few users and performance measurements are hardly done. In response to the kind of challenge reported by SM01, an approach used by another study (SM09) was to combine 2 discounted usability methods into a single method called Rapid Iterative Test and Evaluation Method (RITE) and Stephen Krug's Usability Testing (Krug), that is, RITE+Krug. The results of SM09 where the combined method was used revealed that tests take only few hours of the stakeholders' time and feedback were quickly received and implemented. However, the new method still needs to be used in more industrial project settings. Talking about industrial settings, SM023 believe organisational conflict, breakdowns, and barriers in terms of usability work can be resolved by "developing the right product (that) requires communication and collaboration between multiple stakeholders." Furthermore, it is important to include end users, based on the fact they have a holistic understanding of their work context. Further 
on informal feedback, SM048 found that although informal feedback is to determine context of use and suggest design approach, users' responsibilities are not clear in Scrum projects. SM055, however, found that usability evaluation could be effectively integrated in Scrum projects through the use of Remote Synchronous User Testing. This kind of approach gives room for timely feedback to be incorporated into the development process. The main challenge is that developers have to be flexible in switching between the traditional face-to-face usability evaluation and remote usability testing.

Contextual issues. Studies SM06, and SM10 reported some contextual challenges for usability works in developing countries. Mentions were made of software development companies in Nigeria (SM06) and Ethiopia (SM10). Specific mentions were made of heterogeneity of users, developers' lack of familiarity with usability methods. These issues appear not to be limited to developing countries. SM66 reported that usability and UX design work in Scrum process is challenging due to limited resources available to development companies and a sheer lack of priority for usability and UX works. A similar study conducted in Denmark (SM07) reported the challenge of shortage of professionals to conduct UX work activities. Furthermore on user feedback, although SM11 reported that users show low motivation at providing feedback and have preference for what is ready for use, this is not necessarily always true and the idea is to promote user ownership of the design. Developers also struggle to understand the contextual information necessary for the systems they are developing when users are reluctant to provide feedback. SM12 reported that user feedback get lost in collocated agile teams, especially between support and product teams. SM16 also reported that capturing and measuring UX feedback is challenging.

In trying to resolve these challenges, an approach reported by study SM10 was to use prototyping technique to get early feedback from users. Similarly, software developers were trained to conduct A/B usability testing in the study by SM07. In SM66, developers were also trained to conduct UX tasks in line with the Scrum principle, which stipulates that team members should be able to perform every work task in projects. Another approach used in another study (SM93) to address the difficulty of incorporating user feedback in agile process, was to include little design upfront (0 Sprint), do lightweight documentation, and conduct parallel tasks. Startups might, all the same, have unique challenges. An approach used by SM11 to address this problem was to develop and evaluate a context-aware feedback system (CAFE). This system is capable of collecting in-situ user feedback and integrates them in a timely manner. The results from the study indicate that users feel more confident to share their feedback while working and as a result, their involvements in projects improve. An approach explored by SM16 was to use self-reporting as a technique to capture users' emotions and results obtained were positive. SM142 described taxonomy of methods that can be used for conducting humancentred design studies as well presented few instances of systems developments where the methods can be applied. SM24 developed and assessed two metrics for determining the effectiveness of integrating HCI activities to software engineering processes. In relation to getting in-situ users' feedback, an approach proposed by SM28 was the cooperative usability testing method. The results of SM28 show that this kind of evaluation gives access to testers work-domain knowledge and experiences as users. Nevertheless, SM88 argued that UX design needs and practices in start-ups are not well understood. A critical question raised was how could start-ups do UX design with little 
resources? An approach used by start-ups for collecting user feedback is by seeking professional advice through personal networks. Start-ups feel they need to collect data from actual usage and user analytics to improve their UX design practice.

Capturing and including usability requirements are another challenge regarding HCI practice. SM10 in their study conducted in Ethiopia revealed that usability has yet to be promoted either in practice or at policy level. Furthermore feedback is not collected from actual users but "IT supporters" who used the software on behalf of actual users. For this reason, SM10 suggest the use of personas to address the challenge of designing for heterogeneous user groups. Authors believe personas can be used to capture usability requirements from users in their context of use. Similarly, SM35 while addressing the link between architectural decisions and usability requirements, proposed scenarios can be used to sort usability issues in software architecture design. SM113 reiterated the fact that usability issues have a real impact on software design. For this reason, SM63 proposed a method - Quality Attribute Workshop (QAW) to support development companies in discovering and documenting usability requirements for successful software architecture design. SM67 proposed a method called UserX Story. UserX Story is an adaptation of user story and user experience. Authors believe such an approach can be employed to mitigate the challenges encountered by development teams to incorporate UX aspects and usability requirements. Similarly, SM129 supported incorporating usability recommendations into user stories. The reason is that usability as critical quality factor can be integrated into user stories, which happens to be a de-facto artifact for communicating agile requirements.

Communication in project teams and stakeholders' collaboration are other aspects where there are challenges in development companies. SM13 revealed a challenge of moving design ahead of development under short time frame in agile processes such as SCRUM. SM93 had in 2007 proposed a method that allows design to be one sprint ahead of coding. SM93 indicated this approach helped to reduce the gap between finding usability problems and acting on those problems by incorporating timely changes into the product. SM134 later in 2016 argued that the within-iteration is a better approach to improve communication between UX specialist and agile developers. The author reveals that the iteration-ahead approach could easily become a mini waterfall process. Furthermore, feedback loop can grow considerably and make change implementation slower and more difficult. For this reason, SM134 proposed a framework - Best of Both Worlds $(\mathrm{BoB})$, which is built on the within-iteration approach and seeks to integrate UX work in agile development better. In their own work, SM13 proposed design studio - a rapid process that allows designers, developers, and other stakeholders to collaborate and explore design alternatives. SM17 and SM38 were concerned about who has the authority to speak in the design process. SM38 argued that quality of interactive software is incomplete without including usability and UX professionals require more explicit role in agile projects and more authority. For this reason, the authors propose UX professionals to have the authority to discard suggestions that end users perceive as not useful. SM17 believe design methods as discourse on practice need more exploration. SM23 argue that development of successful products requires communication and collaboration between multiple stakeholders. Furthermore, end users should be part of this collaboration since end users fully understand their work environment. Authors revealed that there has to be organization and process change in order to achieve this collaboration. User centred 
design is a way to achieve this change. In their work, SM57 reveal that task allocation between UX professional and developers is a major challenge in agile projects especially in enterprise systems development and suggest a task-oriented approach for projects with minimal UX resources. Similarly, SM82 reiterate the roles of UX professionals are not well defined in project teams. SM65 reveal that the work setting in which professionals and agile developers work together and collaborate is unclear. Similarly, SM139 reiterate the course of collaboration is also unclear. For this reasons, SM65 suggest explicating contextual values in order to improve work setting and SM139 proposed a crossdiscipline user interface design lifecycle. SM117 demonstrated that user interface transition diagram (UITD) - a modeling notation can be used to improve communication between stakeholders in software development projects. In the same vein SM127 proposed Ripple - a framework for usability engineers and developers co-existing in cooperative and complementary roles.

From the foregoing, it can be seen that one of the major challenges in conducting usability and UX works in development companies is how to effectively collect user feedback in timely manner and integrate them in development process. It is promising to see that some approaches such as remote usability testing, cooperative usability testing, context-aware feedback system, etc. have been proposed and applied. However, it is still unclear whether the challenges of collecting and integrating user feedback are more prominent in agile processes than other processes. Furthermore, what challenges do users' pose aside their heterogeneity? Are existing approaches sufficient enough for all contexts? What discount usability and UX methods are promising for start-ups and Small to Medium Enterprises (SMEs)? There are many pressing challenges as can been from Table 7. The challenges seem inexhaustible. Overall, communication in teams and collaboration among stakeholders, capturing and including usability requirements, and incorporating user feedback appear to be more pressing.

\subsection{Threats to validity}

The major threats to the validity of this study are identifying relevant publications, and data extraction and classification. There are discussed in turn.

\subsubsection{Identifying relevant publications}

It is not possible to include all studies published in the period covered in this study. Basically, this study was guided by its inclusion and exclusion criteria. It is possible that some papers were automatically excluded due to the scope of the study and the search string. Some potential studies were written in languages other than English and automatically excluded. Some relevant studies were published after the conclusion of the literature search and not included. It is also possible that areas where we have witnessed low level of publication have been published in other sources. Further, we rely only on finding relevant papers through searching on the digital libraries listed in Table 4 and by manually searching some conference proceedings available to us. However, we feel confident that the sources where our search has been conducted enhanced the reliability of our results. These sources publish most of the research papers in HCI practice in relation to software engineering processes. Furthermore, we examined previous similar studies and are confident we have explored the relevant sources.

\subsubsection{Data extraction and classification}


The most challenging aspect of data extraction and classification process is classifying the primary studies by topic because of the intricate nature of $\mathrm{HCI} /$ software engineering papers. This implies there could be some level of subjectivity with classifying papers by topic. Thus, it is possible that if the study is repeated there could be some degree of variation with the topics. It is a commonly known fact that classification of papers is not mutually exclusive (Ivarsson \& Gorschek, 2009). In order to mitigate this situation, paper abstracts, introduction, discussion, and conclusions were read iteratively and classified by topic, and this was discussed among the researchers and refined. We also mitigate this risk by utilizing the third researcher as an internal reviewer and the fourth author as an external reviewer. On the other hand, the classifications by research type and contributions were adapted from Wieringa et al. (2006) and Mujtaba et al. (2008) respectively. This gives us some confidence regarding the level of reliability of our study classification.

\subsection{Implications for research and practice}

For researchers, various issues such as adaption of HCI techniques to context, integration of usability requirement in software architecture design, incorporating user feedback in Agile UCD, among others present some opportunities for future research. As efforts are geared towards proposing solutions that could be deployed in practice, there is a need to validate these proposals. Some topics such as cross-cultural design, post-deployment activities and software maintenance, and domain and knowledge have also received little attention and they need to be considered by future research. There is sparse consideration for research on metrics. Metrics are important measurement standards or functions for determining whether a software system has certain properties or meets certain design thresholds. There appears to be a lack of focus on how HCI concepts are being implemented in design of software systems. HCI researchers could also be interested to know why HCI research results are used or not used in industry.

For practitioners, the major problem with software development process is that sometimes when products are deployed for use, they are still found unusable and not meeting certain human values such as accessibility support, identity, inclusiveness, and so on. The reason in many cases is usually due to neglect of human considerations and values. Practitioners can avail themselves of the opportunities HCI practice research papers provide. Practitioners can also take advantage of the findings of this study, especially solutions proposed to mitigate some known challenges discussed in section 6.6. For example, practitioners could benefit from using the various techniques and methods presented in Figure 5 (A-C) at appropriate stages of their development processes.

\section{Conclusions}

HCI practice research has emerged slowly and steadily beginning from the studies of Nielsen, Norman and Draper, and Winograd. However, there still appears to be a lack of coordination in HCI practices of how techniques or methods are being applied to the software development processes and what challenges are being experienced and there is a need for a systematic mapping study to produce a map outlining the HCI practice research landscape. Six questions were raised and mapped with specific goals to identify existing studies on HCI practice and structure them in such a way that outlines the HCI practice research landscape and what challenges are prevailing in companies. This study 
analyzed 142 primary studies, identified from 2384 papers initially found through automatic search of digital libraries and an additional 43 papers found manually. Our systematic map presents state-of-the-art HCI practice research in relation to software development since 2000. The overarching goal was to provide an overview of research topics, determine the methods and type of research and available results.

HCI practice research has emerged more prominently since 2012. Conference papers represented by $58 \%$ formed the bulk of the 142 papers reviewed. Evaluation research seems dominant in HCI practice research and topics such as design tools and techniques, design methods and contexts, design work and organizational culture, and collaboration and team communication are prevalent. The majority of these also contributed to methods and processes of software engineering in relation to HCI. There were more studies, which used mixed methods than single use, and this is promising for HCI practice research because of the complex nature of software development practice. The interview method appears to be predominant in HCI practice research. Case study and survey methods are also widely used. HCI techniques appear to be increasing in adoption in software development companies as well as in projects. Techniques such as persona, scenario, interview, contextual inquiry, focus group and survey are being predominantly used in the planning, analysis, and requirement phase. Prototyping appears to be the predominantly used technique in the mid phase, while heuristic evaluation, think aloud, expert review, and cognitive walkthrough are used in the end phase. Overall, it appears more HCI techniques are used in the start phase compare to the mid and end phases. HCI practice cuts across a wide variety of interactive systems development and has been adopted in the development of web and mobile applications, information/management systems as well as assistive technologies.

There are a couple of issues regarding user feedback, usability requirement, process adaption, and stakeholders' collaboration among others and these create some challenges. The challenges presented in Table 7 provide some opportunities for future research. For example, it could be interesting to know how knowledge is created and shared in teams. How is knowledge created and shared in on-site, off-site, and geographically dispersed teams? What kind of knowledge is created and shared in various categories of team? Does knowledge sharing foster team communication and to what extent?

\section{References}

Ardito, C., Buono, P., Caivano, D., Costabile, M. F., \& Lanzilotti, R. (2014). Investigating and promoting UX practice in industry: An experimental study. International Journal of Human-Computer Studies, 72(6), 542-551. http://doi.org/10.1016/j.ijhcs.2013.10.004

Bark, I., Følstad, A., \& Gulliksen, J. (2006). Use and Usefulness of HCI Methods: Results from an Exploratory Study among Nordic HCI Practitioners. In T. McEwan, J. Gulliksen, \& D. Benyon (Eds.), Proceedings of HCI 2005 (pp. 201-217). London: Springer. http://doi.org/10.1007/1-84628-249-7_13

Bertholdo, A. P. O., Da Silva, T. S., De O. Melo, C., Kon, F., \& Silveira, M. S. (2014). Agile usability patterns for UCD early stages. In Proceedings of DUXU 2014 Conference (Vol. 8517 LNCS, pp. 33-44). Springer. http://doi.org/10.1007/978-3319-07668-3_4 
Bødker, S., \& Christiansen, E. (2004). Designing for Ephemerality and Prototypicality. In Proceedings of the 5th conference on Designing interactive systems: processes, practices, methods, and techniques (DIS '04) (pp. 255-260). http://doi.org/10.1145/1013115.1013151

Brhel, M., Meth, H., Maedche, A., \& Werder, K. (2015). Exploring principles of usercentered agile software development: A literature review. Information and Software Technology, 61, 163-181. http://doi.org/10.1016/j.infsof.2015.01.004

Brown, T. (2008). Design thinking. Harvard Business Review, 86, 1-9.

Brown, T. (2009). Change by design: How design thinking transforms organizations and inspires innovation. HarperCollins.

Bruun, A., \& Stage, J. (2012). Overcoming the Developer Mindset Barrier-Towards Usability Evaluations. In Proceedings of the Information System Research Seminar in Scandinavia (pp. 1-13).

Candy, L. (2006). Practice Based Research: A Guide. Sydney.

Chilana, P. K., Ko, A. J., \& Wobbrock, J. O. (2015). From User - Centered to Adoption Centered Design: A Case Study of an HCI Research Innovation Becoming a Product. In In Proceedings of CHI 2015 (pp. 1-10). Seoul: ACM.

Chilana, P. K., Ko, A. J., Wobbrock, J. O., Grossman, T., \& Fitzmaurice, G. (2011). PostDeployment Usability: A Survey of Current Practices. In Proceedings of the 2011 annual conference on Human factors in computing systems - CHI '11 (pp. 22432246). Vancouver, BC: ACM Press. http://doi.org/10.1145/1978942.1979270

Cockton, G. (2004). Value-Centred HCI. In Proceedings of the third Nordic conference on Human-computer interaction, Tampere, Finland (pp. 149-160).

D'Ippolito, B. (2014). The importance of design for firms' competitiveness: A review of the literature. Technovation, 1-15. http://doi.org/10.1016/j.technovation.2014.01.007

Da Mota Silveira Neto, P. A., Carmo MacHado, I. Do, McGregor, J. D., De Almeida, E. S., \& De Lemos Meira, S. R. (2011). A systematic mapping study of software product lines testing. Information and Software Technology, 53(5), 407-423. http://doi.org/10.1016/j.infsof.2010.12.003

Dighe, S., \& Joshi, A. (2014). An Autoethnographic Study of HCI Effort Estimation in Outsourced Software Development. In Proceedings of the 5th International Conference on Human-Centered Software Engineering (pp. 19-35). Paderborn: Springer.

Downey, L. L. (2007). Group Usability Testing: Evolution in Usability Techniques. Journal of Usability Studies, 2(3), 133-144.

Dybå, T., \& Dingsøyr, T. (2008). Empirical studies of agile software development: A systematic review. Information and Software Technology, 50(9-10), 833-859. http://doi.org/10.1016/j.infsof.2008.01.006

Fernandez, A., Insfran, E., \& Abrahão, S. (2011). Usability evaluation methods for the web: A systematic mapping study. Information and Software Technology, 53(8), 789-817. http://doi.org/10.1016/j.infsof.2011.02.007

Ferre, X., \& Medinilla, N. (2007). How a Human-Centered Approach Impacts Software Development. In Proceedings of the 2007 HCII conference (pp. 68-77). Berlin: Springer-Verlag Berlin Heidelberg.

Ferre, X., \& Moreno, A. M. (2004). Improving software engineering practice with HCI 
aspects development process. Software Engineering Research and Application, 3026, 349-363.

Gulliksen, J., Cajander, Å., Sandblad, B., Eriksson, E., \& Kavathatzopoulos, I. (2009). User-centred systems design as organizational change: A longitudinal action research project to improve usability and the computerized work environment in a public authority. International Journal of Technology and Human Interaction (IJTHI), 5(3), 13-53. http://doi.org/urn:nbn:se:uu:diva-100307

Harning, M. B., \& Vanderdonckt, J. (2003). Closing the Gaps: Software Engineering and Human-Computer Interaction. Louvain-la-Neuve, Belgium: Université catholique de Louvain, Institut d'Administration et de Gestion (IAG).

Hayes, G. R. (2014). Knowing by Doing: Action Research as an Approach to HCI. In J. Olson \& W. Kellogg (Eds.), Ways of Knowing in HCI (pp. 49-68). New York: Springer. http://doi.org/DOI 10.1007/978-1-4939-0378-8_3

Hess, J., Randall, D., Pipek, V., \& Wulf, V. (2013). Involving users in the wildparticipatory product development in and with online communities. International Journal of Human-Computer Studies, 71(5), 570-589. http://doi.org/10.1016/j.ijhcs.2013.01.003

Hewett, T., Baecker, R., Card, S., Carey, T., Gasen, J., Mantei, M., ... Verplank, W. (1996). ACM SIGCHI Curricula for Human-Computer Interaction. New York.

Hochheiser, H., \& Lazar, J. (2007). HCI and Societal Issues: A Framework for Engagement. International Journal of Human-Computer Interaction, 23(3), 339374. http://doi.org/10.1080/10447310701702717

Hudson, S. E., \& Mankoff, J. (2014). Concepts, Values, and Methods for Technical Human-Computer Interaction Research. In J. S. Olson \& W. A. Kellogg (Eds.), Ways of Knowing in HCI (pp. 69-93). New York: Springer.

Inayat, I., Salwah, S., Marczak, S., Daneva, M., \& Shamshirband, S. (2015). A systematic literature review on agile requirements engineering practices and challenges. Computers in Human Behavior, 51, 915-929.

ISO. (1999). ISO 13407. Human-centred design processes for interactive systems. Geneve, Switzerland.

ISO. (2010). Ergonomics of Human-System Interaction - Part 210: Human-Centred Design for Interactive Systems. In ISO 9241-210:2010 (pp. 1-32). ISO. Retrieved from https://www.iso.org/obp/ui/\#iso:std:iso:9241:-210:ed-1:v1:en

Ivarsson, M., \& Gorschek, T. (2009). Technology transfer decision support in requirements engineering research: A systematic review of $\mathrm{REj}$. Requirements Engineering, 14(3), 155-175. http://doi.org/10.1007/s00766-009-0080-1

John, B. E., Kazman, R., Chen, E., \& Marcus, A. (2004). Identifying gaps between HCI, software engineering, and design, and boundary objects to bridge them. In Proceedings of CHI 2004 Extended Abstracts on Human Factors in Computing Systems (pp. 1723-1724). New York: ACM Press.

Johnson, R. B., \& Onwuegbuzie, A. J. (2004). Mixed methods research: a research paradigm whose time has come. Educational Researcher, 33(7), 14-26.

Kaasinen, E., Roto, V., Hakulinen, J., Heimonen, T., Jokinen, J. P. P., Karvonen, H., ... Turunen, M. (2015). Defining user experience goals to guide the design of industrial systems. Behaviour \& Information Technology, 34(10), 976-991. http://doi.org/10.1080/0144929X.2015.1035335 
Kitchenham, B., \& Charters, S. (2007). Guidelines for performing Systematic Literature Reviews in Software Engineering. Technical Report EBSE 2007-001 (Vol. 2). Durham.

Kotzé, P. (2002). Directions in HCI Education, Research, and Practice in Southern Africa. In CHI '02 extended abstracts on Human factors in computing systems - CHI '02 (pp. 524-525). http://doi.org/10.1145/506443.506462

Law, E. L.-C., \& Lárusdóttir, M. K. (2015). Whose experience do we care about? Analysis of the fitness of scrum and kanban to user experience. International Journal of Human-Computer Interaction, 31(9), 584-602. http://doi.org/10.1080/10447318.2015.1065693

Liem, A., \& Sanders, E. B. (2011). The Impact of Human-Centred Design Workshops in Strategic Design Projects. In Proceedings of the HCII 2011 Conference (pp. 110119). Orlando, FL, USA: Springer.

Ludi, S. (2003). Undergraduate Software Engineering Curriculum Enhancement via Human- Computer Interaction. In 25th IEEE International Conference on Software Engineering, ICSE 2003 (pp. 72-75).

Maguire, M. (2013). Using Human Factors Standards to Support User Experience and Agile Design. In Proceedings of the UAHCI/HCII 2013 (pp. 185-194).

Majid, R. A., Noor, N. L., Adilah, W., \& Adnan, W. (2012). Strengthening the HCI Approaches in the Software Development Process. World Academy of Science, Engineering and Technology, 64, 373-377.

Majid, R. A., Noor, N. L. M., Adnan, W. A. W., \& Mansor, S. (2009). A survey on HCI considerations in the software development life cycle. In Proceedings of the 2nd International Conference on Interaction Sciences Information Technology, Culture and Human - ICIS '09 (Vol. 403, pp. 21-24). http://doi.org/10.1145/1655925.1655929

Mcginley, C., \& Macredie, R. (2011). Towards Diversity and Empathy in Design Development. zoonTechnica - the Journal of Redirective Design, (1), 1-10.

Memmel, T., Gundelsweiler, F., \& Reiterer, H. (2007). Agile Human-Centered Software Engineering. In Proceedings of HCI 2007 Conference (pp. 1-9). Swinton, UK: British Computer Society.

Molina, F., \& Toval, A. (2009). Integrating usability requirements that can be evaluated in design time into Model Driven Engineering of Web Information Systems. Advances in Engineering Software, 40, 1306-1317. http://doi.org/10.1016/j.advengsoft.2009.01.018

Mosqueira-Rey, E., Alonso-Ríos, D., \& Moret-Bonillo, V. (2009). Usability taxonomy and context-of-use taxonomy for usability analysis. In Conference Proceedings IEEE International Conference on Systems, Man and Cybernetics (pp. 812-817). http://doi.org/10.1109/ICSMC.2009.5346929

Mujtaba, S., Petersen, K., Feldt, R., \& Mattsson, M. (2008). Software product line variability: A systematic mapping study.

Myers, B. a., \& Rosson, M. B. (1992). Survey on user interface programming. In Proceedings of the SIGCHI conference on Human factors in computing systems CHI '92 (pp. 195-202). New York, New York, USA: ACM Press. http://doi.org/10.1145/142750.142789

Nielsen, J. (1993). Usability Engineering. London, UK: Academic Press. 
Nivala, A. M., Tiina Sarjakoski, L., \& Sarjakoski, T. (2007). Usability methods' familiarity among map application developers. International Journal of Human Computer Studies, 65(9), 784-795. http://doi.org/10.1016/j.ijhcs.2007.04.002

Norman, D. A., \& Draper, S. W. (1986). User Centered System Design: New Perspectives on Human-computer Interaction. (D. A. Norman \& S. W. Draper, Eds.). Taylor \& Francis.

Ogunyemi, A., \& Lamas, D. (2014). Interplay between Human-Computer Interaction and Software Engineering. In Proceedings of the 9th Iberian Conference on Information Systems and Technologies (pp. 1-10). Barcelona: IEEE Xplore. http://doi.org/10.1109/CISTI.2014.6877024

Ogunyemi, A., Lamas, D., Adagunodo, E. R., \& Rosa, I. B. da. (2015). HCI Practices in the Nigerian software industry. In J. Abascal, S. Barbosa, M. Fetter, T. Gross, P. Palanque, \& M. Winckler (Eds.), Proceedings of INTERACT 2015 conference (Vol. 9297, pp. 479-488). Cham: Springer International Publishing. http://doi.org/10.1007/978-3-319-22668-2

Øvad, T., \& Larsen, L. B. (2016). Templates: A Key to Success When Training Developers to Perform UX Tasks. In G. Cockton, M. Lárusdóttir, P. Gregory, \& $\AA$. Cajander (Eds.), Integrating User-Centred Design in Agile Development (pp. 7796). Zurich: Springer. http://doi.org/10.1007/978-3-319-32165-3_3

Paternoster, N., Giardino, C., Unterkalmsteiner, M., Gorschek, T., \& Abrahamsson, P. (2014). Software development in startup companies: A systematic mapping study. Information and Software Technology, 56(10), 1200-1218. http://doi.org/10.1016/j.infsof.2014.04.014

Petersen, K., Feldt, R., Mujtaba, S., \& Mattsson, M. (2008). Systematic mapping studies in software engineering. In In Proceedings of the 12th international conference on Evaluation and Assessment in Software Engineering (EASE'08) (pp. 68-77). Swinton, UK: British Computer Society. Retrieved from https://www.isl.ce.yildiz.edu.tr/personal/maktas/file/3599/systemticmapping.pdf

Petersen, K., Vakkalanka, S., \& Kuzniarz, L. (2015). Guidelines for conducting systematic mapping studies in software engineering: An update. Information and Software ..., 64, 1-18. http://doi.org/http://dx.doi.org/10.1016/j.infsof.2015.03.007

Rex Hartson, H. (1998). Human-computer interaction: Interdisciplinary roots and trends. Journal of Systems and Software, 43(2), 103-118. http://doi.org/http://dx.doi.org/10.1016/S0164-1212(98)10026-2

Rosenberg, D. (2014). Introducing the business of UX. Interactions, 74-76.

Rozanski, E. P., \& Haake, A. R. (2003). The Many Facets of HCI. In In Proceedings of the CITC4 2003 (pp. 180-185). ACM.

Salvador, C., Nakasone, A., \& Pow-Sang, J. A. (2014). A systematic review of usability techniques in agile methodologies. In Proceedings of the 7th Euro American Conference on Telematics and Information Systems - EATIS '14 (pp. 1-6). http://doi.org/10.1145/2590651.2590668

Sener, B., \& Wormald, P. (2008). User evaluation of HCI concepts for defining product form. Design Studies, 29(1), 12-29. http://doi.org/10.1016/j.destud.2007.06.003

Sousa, K. S., \& Furtado, E. (2003). RUPi - a unified process that integrates humancomputer interaction and software engineering. In Proceedings of the International Conference on Software Engineering - ICSE'2003, (p. 41-48.). 
Sutcliffe, A. G., \& Carroll, J. M. (1999). Designing claims for reuse in interactive systems design. International Journal of Human Computer Studies, 50(3), 213-241. http://doi.org/10.1006/ijhc.1999.0245

Sy, D. (2007). Adapting Usability Investigations for Agile User-centered Design. Journal of Usability Studies, 2(3), 112-132.

Vermeeren, A., \& Cockton, G. (2013). Facilitating the Take-up of New HCI Practices : A Diffusion of Innovations 'Perspective. In Proceedings of the Workshop Made for sharing: HCI Stories of Transfer, Triumph and Tragedy, CHI 2013 Conference (pp. 1-6). Paris, France: ACM.

Walenstein, A. (2003). Finding Boundary Objects in SE and HCI: An Approach Through Engineering-oriented Design Theories. In 25th IEEE International Conference on Software Engineering, ICSE 2003 (pp. 92-99).

Wendler, R. (2012). The maturity of maturity model research: A systematic mapping study. Information and Software Technology, 54, 1317-1339. http://doi.org/10.1016/j-infsof.2012.07.007

Wieringa, R., Maiden, N., Mead, N., \& Rolland, C. (2006). Requirements engineering paper classification and evaluation criteria: a proposal and a discussion. Requirements Engineering, 11, 102-107. http://doi.org/10.1007/s00766-005-0021-6

Winograd, T. (1997). The Design of Interaction. In P. Denning \& R. Metcalfe (Eds.), Beyond Calculation: The Next Fifty Years of Computing (pp. 149-162). SpringerVerlag.

Zapata, C. (2015). Integration of Usability and Agile Methodologies: A Systematic Review. In Proceedings of DUXU 2015 conference (Vol. LNCS 9186, pp. 368378). Springer. http://doi.org/10.1007/978-3-319-20886-2

Zimmerman, J., Forlizzi, J., \& Evenson, S. (2007). Research Through Design as a Method for Interaction Design Research in HCI design research in HCI. In Proceedings of the SIGCHI conference on Human factors in computing systems (pp. 493-502). http://doi.org/http://doi.acm.org/10.1145/1240624.1240704

Zoltowski, C. B. (2010). Students' Ways of Experiencing Human-Centered Design. Purdue University West Lafayette, Indiana. 


\section{Appendix A: References of Cited Included papers}

SM01 Lárusdóttir, M., Cajander, Å., \& Gulliksen, J. (2014). Informal feedback rather than performance measurements - user-centred evaluation in Scrum projects. Behaviour \& Information Technology, 33(11), 1118-1135. http://doi.org/10.1080/0144929X.2013.857430

SM02 Gulliksen, J., Göransson, B., Boivie, I., Blomkvist, S., Persson, J., \& Cajander, Å. (2003). Key Principles for User-Centred Systems Design. Behaviour \& Information Technology, 22(6), $397-$ 409. http://doi.org/10.1080/01449290310001624329

SM03 Ji, Y. G., \& Yun, M. H. (2006). Enhancing the Minority Discipline in the IT Industry: A Survey of Usability and User-Centered Design Practice. International Journal of Human- Computer Interaction, 20(2), 117-134. http://doi.org/10.1207/s15327590ijhc2002

SM04 Kaasinen, E., Roto, V., Hakulinen, J., Heimonen, T., Jokinen, J. P. P., Karvonen, H., ... Turunen, M. (2015). Defining user experience goals to guide the design of industrial systems. Behaviour \& Information Technology, 34(10), 976-991. http://doi.org/10.1080/0144929X.2015.1035335

SM05 Law, E. L.-C., \& Lárusdóttir, M. K. (2015). Whose Experience Do We Care About? Analysis of the Fitness of Scrum and Kanban to User Experience. International Journal of Human-Computer Interaction, 31(9), 584-602. http://doi.org/10.1080/10447318.2015.1065693

SM06 Ogunyemi, A. A., Lamas, D., Adagunodo, E. R., Loizides, F., \& Da Rosa, I. B. (2016). Theory, Practice and Policy: An Inquiry into the Uptake of HCI Practices in the Software Industry of a Developing Country. International Journal of Human-Computer Interaction, 32(9), 665-681. http://doi.org/10.1080/10447318.2016.1186306

SM07 Øvad, T., Bornoe, N., Lars, B. L., \& Stage, J. (2015). Teaching Software Developers to Perform UX Tasks. In Proceedings of OzCHI 2015 (pp. 397-406). Melbourne: ACM. http://doi.org/DOI: http://dx.doi.org/10.1145/2838739.2838764

SM08 Grigoreanu, V., \& Mohanna, M. (2013). Informal Cognitive Walkthrough (ICW): Paring down and pairing up for an agile world. In Conference on Human Factors in Computing Systems Proceedings (pp. 3093-3096). Paris: ACM. http://doi.org/10.1145/2470654.2466421

SM09 Mcginn, J., \& Ramirez Chang, A. (2013). RITE + Krug: A Combination of Usability Test Methods for Agile Design. Journal of Usability Studies, 8(3), 61-68.

SM10 Teka, D., Dittrich, Y., \& Kifle, M. (2016). Usability Challenges in an Ethiopian Software Development Organization. In Proceedings of the 9th International Workshop on Cooperative and Human Aspects of Software Engineering (pp. 114-120). Austin, TX: ACM. http://doi.org/http://dx.doi.org/10.1145/2897586.2897604

SM11 Dzvonyar, D., Krusche, S., Alkadhi, R., \& Bruegge, B. (2016). Context-aware user feedback in continuous software evolution. In Proceedings of the International Workshop on Continuous Software Evolution and Delivery - CSED '16 (pp. 12-18). Austin, TX: ACM. http://doi.org/10.1145/2896941.2896952

SM12 Lee, M. J., \& Ko, A. J. (2012). Representations of user feedback in an agile, collocated software team. In 5th International Workshop on Co-operative and Human Aspects of Software Engineering, CHASE 2012 - Proceedings (pp. 76-82). Zurich: IEEE. http://doi.org/10.1109/CHASE.2012.6223028

SM13 Ungar, J., \& White, J. (2008). Agile User Centered Design: Enter the Design Studio - a Case Study. In Extended Abstracts on Human Factors in Computing Systems (CHI '08) (pp. 21672178). Florence: ACM. http://doi.org/10.1145/1358628.1358650

SM14 Ferrario, M. A., Simm, W., Newman, P., Forshaw, S., \& Whittle, J. (2014). Software engineering for "social good": integrating action research, participatory design, and agile development. In Proceedings of the 36th International Conference on Software Engineering - ICSE 2014 (pp. 520523). Hyderabad: ACM. http://doi.org/10.1145/2591062.2591121

SM15 Walsh, T., \& Nurkka, P. (2012). Approaches to cross-cultural design: Two Case Studies with UX Web-Surveys. In Proceedings of the 24th Australian Computer-Human Interaction Conference (pp. 633-642). Melbourne: ACM. http://doi.org/10.1145/2414536.2414632

SM16 Garcia, S. E., \& Hammond, L. M. (2016). Capturing and Measuring Emotions in UX. In Proceedings of the 2016 CHI Conference Extended Abstracts on Human Factors in Computing Systems - CHI EA '16 (pp. 777-785). San Jose, CA: ACM. http://doi.org/10.1145/2851581.2851605 
SM17 Cohn, M. L., Sim, S. E., \& Dourish, P. (2010). Design methods as discourse on practice. In Proceedings of the GROUP'10 (pp. 45-54). Sanibel Island, Florida: ACM. http://doi.org/10.1145/1880071.1880079

SM21 Andreasson, R., Lindblom, J., \& Thorvald, P. (2015). Towards an increased degree of usability work in organizations. Procedia Manufacturing, 3, 5739-5746. http://doi.org/10.1016/j.promfg.2015.07.814

SM22 Gulliksen, J., Boivie, I., \& Göransson, B. (2006). Usability professionals-current practices and future development. Interacting with Computers, 18(4), 568-600. http://doi.org/10.1016/j.intcom.2005.10.005

SM23 Winter, J., Rönkkö, K., \& Rissanen, M. (2014). Identifying organizational barriers - A case study of usability work when developing software in the automation industry. Journal of Systems and Software, 88(1), 54-73. http://doi.org/10.1016/j.jss.2013.09.019

SM24 Joshi, A., Sarda, N. L., \& Tripathi, S. (2010). Measuring effectiveness of HCI integration in software development processes. Journal of Systems and Software, 83(11), 2045-2058. http://doi.org/10.1016/j.jss.2010.03.078

SM25 Bruun, A., \& Stage, J. (2015). New approaches to usability evaluation in software development: barefoot and crowdsourcing. Journal of Systems and Software, 105, 40-53. http://doi.org/10.1016/j.jss.2015.03.043

SM27 Jokela, T. (2004). Evaluating the user-centredness of development organisations: Conclusions and implications from empirical usability capability maturity assessments. Interacting with Computers, 16(6), 1095-1132. http://doi.org/10.1016/j.intcom.2004.07.006

SM28 Følstad, A., \& Hornbæk, K. (2010). Work-domain knowledge in usability evaluation: Experiences with Cooperative Usability Testing. Journal of Systems and Software, 83(11), 2019-2030. http://doi.org/http://dx.doi.org/10.1016/j.jss.2010.02.026

SM29 Iivari, N. (2006). "Representing the User" in software development - a cultural analysis of usability work in the product development context. Interacting with Computers, 18(4), 635-664. http://doi.org/10.1016/j.intcom.2005.10.002

SM30 Nivala, A. M., Tiina Sarjakoski, L., \& Sarjakoski, T. (2007). Usability methods' familiarity among map application developers. International Journal of Human Computer Studies, 65(9), 784-795. http://doi.org/10.1016/j.ijhcs.2007.04.002

SM31 Boivie, I., Gulliksen, J., \& G?ransson, B. (2006). The lonesome cowboy: A study of the usability designer role in systems development. Interacting with Computers, 18(4), 601-634. http://doi.org/10.1016/j.intcom.2005.10.003

SM32 Boivie, I., Åborg, C., Persson, J., \& Löfberg, M. (2003). Why usability gets lost or usability in inhouse software development. Interacting with Computers, 15(4), 623-639. http://doi.org/10.1016/S0953-5438(03)00055-9

SM33 Howarth, J., Smith-jackson, T., \& Hartson, R. (2009). Supporting novice usability practitioners with usability engineering tools. Int. J. Human-Computer Studies, 67, 533-549. http://doi.org/10.1016/j.ijhcs.2009.02.003

SM34 Bygstad, B., Ghinea, G., \& Brevik, E. (2008). Software Development Methods and Usability: Perspectives from a Survey in the Software Industry in Norway. Interacting with Computers, 20(3), 375-385. http://doi.org/10.1016/j.intcom.2007.12.001

SM35 Rafla, T., Robillard, P. N., \& Desmarais, M. (2006). Investigating the impact of usability on software architecture through scenarios: A case study on Web systems. Journal of Systems and Software, 79(3), 415-426. http://doi.org/10.1016/j.jss.2005.10.014

SM36 Ardito, C., Buono, P., Caivano, D., Costabile, M. F., \& Lanzilotti, R. (2014). Investigating and Promoting UX Practice in Industry: An Experimental Study. International Journal of HumanComputer Studies, 72(6), 542-551. http://doi.org/10.1016/j.ijhcs.2013.10.004

SM37 Kline, R. B., \& Seffah, A. (2005). Evaluation of integrated software development environments: Challenges and results from three empirical studies. International Journal of Human-Computer Studies, 63(6), 607-627. http://doi.org/10.1016/j.ijhcs.2005.05.002

SM38 3 Larusdottir, M., Gulliksen, J., \& Cajander, A. (2017). A license to kill - Improving UCSD in Agile

${ }^{3}$ SM38 - has been available online since 28 January 2016 
development. Journal of Systems and Software, 123, 214-222. http://doi.org/10.1016/j.jss.2016.01.024

SM39 Salah, D., Paige, R., \& Cairns, P. (2014b). Integrating Agile Development and User Centred Design- A Place for Usability Maturity Models? In 5th IFIP WG 13.2 International Conference, HCSE 2014, Proceedings (pp. 108-125). Paderborn: Springer. http://doi.org/10.1007/978-3-66244811-3

SM40 Ardito, C., Baldassarre, M. T., Caivano, D., \& Lanzilotti, R. (2016). Integration of HumanCentred Design and Agile Software Development Practices: Experience Report from a SME. In G. Cockton, M. Lárusdóttir, P. Gregory, \& A.. Cajander (Eds.), Integrating User-Centred Design in Agile Development (pp. 117-135). Zurich: Springer. http://doi.org/10.1007/978-3-319-32165-3 1

SM41 Hussain, Z., Holzinger, A., \& Slany, W. (2009). Current State of Agile User-Centered Design : A Survey. In Proceedings of the 5th Symposium of the Workgroup Human-Computer Interaction and Usability Engineering of the Austrian Computer Society on HCI and Usability for e-Inclusion (pp. 416-427). Linz: Springer. http://doi.org/10.1007/978-3-642-10308-7 30

SM42 Bornoe, N., \& Stage, J. (2014). Usability Engineering in the Wild: How do Practitioners Integrate Usability Engineering in Software Development? In Proceedings of the 5th International Conference on Human-Centred Software Engineering (pp. 199-216). Paderborn: Springer. http://doi.org/10.1007/978-3-662-44811-3 12

SM43 Raison, C., \& Schmidt, S. (2013). Keeping user centred design (UCD) alive and well in your organisation: Taking an agile approach. In Proceedings of DUXU/HCII Conference (Vol. 8012 LNCS, pp. 573-582). Las Vegas, NV: Springer. http://doi.org/10.1007/978-3-642-39229-0_61

SM44 Haesen, M., Coninx, K., Bergh, J. Van Den, \& Luyten, K. (2008). MuiCSer: A Process Framework for Engineering Processes. In Proceedings of HCSE/TAMODIA 2008 (pp. 150-165). Pisa: Springer. http://doi.org/10.1007/978-3-540-85992-5 14

SM45 Bordin, S., \& De Angeli, A. (2016). Communication Breakdowns in the Integration of UserCentred Design and Agile Development. In G. Cockton, M. Lárusdóttir, P. Gregory, \& Å. Cajander (Eds.), Integrating User-Centred Design in Agile Development (pp. 137-161). Zurich: Springer. http://doi.org/10.1007/978-3-319-32165-3 _6

SM46 Hussain, Z., Slany, W., \& Holzinger, A. (2009). Investigating Agile User-Centered Design in Practice: A Grounded Theory Perspective. In Proceedings of the 5th Symposium of the Workgroup Human-Computer Interaction and Usability Engineering of the Austrian Computer Society, USAB 2009 (Vol. 5889, pp. 279-289). Linz: Springer. http://doi.org/10.1007/978-3-642-10308-7_19

SM47 Jia, Y., Larusdottir, M. K., \& Cajander, A. (2012). The Usage of Usability Techniques in Scrum Projects. In Proceedings of the 4th International Conference, HCSE 2012 (pp. 331-341). Toulouse: Springer. http://doi.org/10.1007/978-3-642-34347-6_25

SM48 Cajander, Å., Larusdottir, M., \& Gulliksen, J. (2013). Existing but not Explicit - The User Perspective in Scrum Projects in Practice. In Proceedings of the 14th IFIP TC 13 International Conference (Vol. 8119 LNCS, pp. 762-779). Cape Town: Springer. http://doi.org/10.1007/978-3642-40477-1_52

SM50 Chamberlain, S., Sharp, H., \& Maiden, N. (2006). Towards a Framework for Integrating Agile Development and User-Centred Design. In P. Abrahamsson, M. Marchesi, \& G. Succi (Eds.), Proceedings of the 7th International Conference, XP 2006, (pp. 143-153). Oulu: Springer. http://doi.org/10.1007/11774129_15

SM51 Tarkkanen, K., Reijonen, P., Tétard, F., \& Harkke, V. (2013). Back to User-Centered Usability Testing. In A. Holzinger, M. Ziefle, M. Hitz, \& M. Debevc (Eds.), Proceedings of the First International Conference, SouthCHI 2013 (pp. 91-106). Maribor: Springer. http://doi.org/10.1007/978-3-642-39062-3_6

SM53 Vukelja, L., Müller, L., \& Opwis, K. (2007). Are Engineers Condemned to Design? A Survey on Software Engineering and UI Design in Switzerland. In Proceedings of the 11th IFIP TC 13 International Conference (INTERACT) (pp. 555-568). Rio de Janeiro: Springer. http://doi.org/10.1007/978-3-540-74800-7_50

SM55 Lizano, F., Sandoval, M. M., \& Stage, J. (2014). Integrating Usability Evaluations into Scrum: A Case Study Based on Remote Synchronous User Testing. In M. Kurosu (Ed.), Proceedings of the 16th International Conference, HCI International 2014 (pp. 500-509). Heraklion, Crete: Springer. http://doi.org/10.1007/978-3-319-07233-3_46

SM56 Lank, E., Withee, K., Schile, L., \& Parker, T. (2006). User Centred Rapid Application 
Development - Springer. In N. Guelfi \& A. Savidis (Eds.), Proceedings of the Second International Workshop, RISE 2005 (pp. 34-49). Heraklion, Crete: Springer. http://doi.org/10.1007/11751113 4

SM57 Kuusinen, K. (2015b). Task Allocation Between UX Specialists and Developers in Agile Software Development Projects. In J. Abascal, S. Barbosa, M. Fetter, T. Gross, P. Palanque, \& M. Winckler (Eds.), Proceedings of the 15th IFIP TC 13 International Conference (INTERACT) (Vol. 9298, pp. 27-44). Bamberg: Springer. http://doi.org/10.1007/978-3-319-22698-9

SM59 Larusdottir, M. K., Bjarnadottir, E. R., \& Gulliksen, J. (2010). The Focus on Usability in Testing Practices in Industry. In Proceedings of the Second IFIP TC 13 Symposium, HCIS 2010, Held as Part of WCC 2010. (pp. 98-109). Brisbane: Springer.

SM60 Hussein, I., Mahmud, M., \& Tap, A. O. (2014). HCI Knowledge for UX Practices in the Web Development Process. In A. Marcus (Ed.), Proceedings of the Third International Conference, DUXU 2014, Held as Part of HCI International 2014 (pp. 116-126). Heraklion, Crete: Springer. http://doi.org/10.1007/978-3-319-07626-3 11

SM62 Billestrup, J., Stage, J., Bruun, A., Nielsen, L., \& Nielsen, K. S. (2014). Creating and using personas in software development: Experiences from practice. In S. Sauer, C. Bogdan, P. Forbrig, R. Bernhaupt, \& M. Winckler (Eds.), Proceedings of the 5th IFIP WG 13.2 International Conference, HCSE 2014 (Vol. 8742, pp. 251-258). Paderborn: Springer. http://doi.org/10.1007/978-3-662-44811-3_16

SM63 Rafla, T., Robillard, P. N., \& Desmarais, M. (2007). A method to elicit architecturally sensitive usability requirements: Its integration into a software development process. Software Quality Journal, 15(2), 117-133. http://doi.org/10.1007/s11219-006-9009-9

SM64 Hiremath, M., \& Sathiyam, V. (2013). Fast Train to DT: A Practical Guide to Coach Design Thinking in Software Industry. In P. Kotzé, G. Marsden, G. Lindgaard, J. Wesson, \& M. Winckler (Eds.), Proceedings of the 14th IFIP TC 13 International Conference INTERACT 2013 (Vol. 8119 LNCS, pp. 780-787). Cape Town: Springer. http://doi.org/10.1007/978-3-642-40477-1_53

SM65 Ferreira, J., Sharp, H., \& Robinson, H. (2010). Values and Assumptions Shaping Agile Development and User Experience Design in Practice. In A. Sillitti, A. Martin, X. Wang, \& E. Whitworth (Eds.), Proceedings of the 11th International Conference, XP 2010 (Vol. 48 LNBIP, pp. 178-183). Trondheim: Springer. http://doi.org/10.1007/978-3-642-13054-0 15

SM66 Øvad, T., \& Larsen, L. B. (2016). Templates: A Key to Success When Training Developers to Perform UX Tasks. In G. Cockton, M. Lárusdóttir, P. Gregory, \& Å. Cajander (Eds.), Integrating User-Centred Design in Agile Development (pp. 77-96). Zurich: Springer. http://doi.org/10.1007/978-3-319-32165-3_3

SM67 Choma, J., Zaina, L. A. M., \& Beraldo, D. (2016). UserX Story: Incorporating UX Aspects into User Stories Elaboration. In M. Kurosu (Ed.), Proceedings of the 18th International Conference, HCI International 2016 (pp. 131-140). Toronto: Springer. http://doi.org/10.1007/978-3-31939510-4_13

SM68 Guo, H. (2016). Lean but not Mean UX: Towards a Spiral UX Design Model. In A. Marcus (Ed.), Proceedings of the 5th International Conference, DUXU 2016, Held as Part of HCI International 2016 (Vol. 9746, pp. 25-33). Toronto: Springer. http://doi.org/10.1007/978-3-319-40409-7_3

SM69 Almahmoud, J., Almalki, A., Alrashed, T., \& Alwabil, A. (2016). Prototyping Complex Systems: A Diary Study Approach to Understand the Design Process. In A. Marcus (Ed.), Proceedings of the 5th International Conference, DUXU 2016, Held as Part of HCI International 2016 (Vol. 9746, pp. 187-196). Toronto: Springer. http://doi.org/10.1007/978-3-319-40409-7_19

SM70 Kuusinen, K. (2015a). Overcoming Challenges in Agile User Experience Work: Cross-Case Analysis of Two Large Software Organizations. In Proceedings of the 41st Euromicro Conference on Software Engineering and Advanced Applications (pp. 454-458). IEEE. http://doi.org/10.1109/SEAA.2015.38

SM71 Salah, D., Paige, R., \& Cairns, P. (2014a). A Practitioner Perspective on Integrating Agile and User Centred Design. In Proceedings of the 28th International BCS Human Computer Interaction Conference on HCI 2014 (pp. 100-109). Southport: ACM. http://doi.org/10.14236/ewic/hci2014.11

SM73 Bark, I., Følstad, A., \& Gulliksen, J. (2006). Use and Usefulness of HCI Methods: Results from an Exploratory Study among Nordic HCI Practitioners. In T. McEwan, J. Gulliksen, \& D. Benyon (Eds.), Proceedings of HCI 2005 (pp. 201-217). London: Springer. http://doi.org/10.1007/1- 
84628-249-7 13

SM74 Kadytė, V., \& Tétard, F. (2004). The role of usability evaluation and usability testing techniques in the development of a mobile system. In Proceedings of the NordiCHI workshop on improving the interplay between usability evaluation and software design (pp. 1-6). Tampere: ACM. Retrieved from http://people.cs.aau.dk/ jans/events/NordiCHI2004WS/kadyte.pdf

SM75 Venturi, G., \& Troost, J. (2004). Survey on the UCD Integration in the Industry. In Proceedings of the third NordiCHI Conference (pp. 449-452). http://doi.org/10.1145/1028014.1028092

SM76 Frøkjær, E., \& Hornbæk, K. (2004). Input from usability evaluation in the form of problems and redesigns : results from interviews with developers. In Proceedings of the Workshop on Improving the Interplay between Usability Evaluation and User Interface Design, NordiCHI 2004 (pp. 1-4). Tampere: ACM.

SM77 Law, E. L. (2004). A Multi-Perspective Approach to Tracking the Effectiveness of User Tests : A Case Study. In K. Hornbæk \& J. Stage (Eds.), In Proceedings of the NordiCHI Workshop on Improving the Interplay Between Usability Evaluation and User Interface Design (Vol. 2004, pp. 36-40). Tampere: ACM.

SM78 Chilana, P. K., Ko, A. J., Wobbrock, J. O., Grossman, T., \& Fitzmaurice, G. (2011). PostDeployment Usability: A Survey of Current Practices. In Proceedings of the 2011 annual conference on Human factors in computing systems - CHI'11 (pp. 2243-2246). Vancouver, BC: ACM Press. http://doi.org/10.1145/1978942.1979270

SM79 Bednarik, R., \& Krohns, J. (2015). User-centred design practice and adoption in smaller ICT companies in Eastern Finland: an interview study. International Journal of Business Information Systems, 18(3), 285. http://doi.org/10.1504/IJBIS.2015.068165

SM80 Metzker, E., \& Reiterer, H. (2007). Integrating Usability Engineering Methods into Existing Software Development Processes via Evidence-Based Usability Engineering. Journal of Human Mediated Interactions, (2004), 1-16.

SM81 Bak, J. O., Nguyen, Ki., Risgaard, P., \& Stage, J. (2008). Obstacles to usability evaluation in practice. In Proceedings of the 5th Nordic conference on Human-computer interaction building bridges - NordiCHI '08 (p. 23). New York, New York, USA: ACM Press. http://doi.org/10.1145/1463160.1463164

SM82 Isomursu, M., Sirotkin, A., Voltti, P., \& Halonen, M. (2012). User Experience Design Goes Agile in Lean Transformation -- A Case Study. In Proceedings of 2012 Agile Conference (pp. 1-10). IEEE. http://doi.org/10.1109/Agile.2012.10

SM83 Kuusinen, K., Mikkonen, T., \& Pakarinen, S. (2012). Agile User Experience Development in a Large Software Organization: Good Expertise but Limited Impact. In M. Winckler, P. Forbrig, \& R. Bernhaupt (Eds.), Proceedings of the 4th International Conference, HCSE 2012 (pp. 94-111). Toulouse: Springer. http://doi.org/10.1007/978-3-642-34347-6_6

SM86 Wale-Kolade, A. Y. (2015). Integrating usability work into a large inter-organisational agile development project: Tactics developed by usability designers. Journal of Systems and Software, 100, 54-66. http://doi.org/10.1016/j.jss.2014.10.036

SM87 Ogunyemi, A., Lamas, D., Sarapuu, H., \& da Rosa, I. B. (2015). Current State of HCI Practice in the Estonian Software Development Industry. In C. Stephanidis (Ed.), Proceedings of the International Conference, HCI International 2015 (Vol. 529, pp. 170-175). Los Angeles: Springer. http://doi.org/10.1007/978-3-319-21383-5_29

SM88 Eshet, E., \& Bouwman, H. (2016). [1] of Use: The Final Frontier in the Practice of User-Centered Design? Interacting with Computers, 1-23. http://doi.org/10.1093/iwc/iww030

SM89 Hokkanen, L., \& Väänänen-Vainio-Mattila, K. (2015). UX Work in Startups: Current Practices and Future Needs. In C. Lassenius, T. Dingsøyr, \& M. Paasivaara (Eds.), Proceedings of the 16th International Conference, XP 2015 (Vol. 212, pp. 81-92). Helsinki: Springer. http://doi.org/10.1007/978-3-319-18612-2_ 7

SM90 Prior, S., Waller, A., Black, R., \& Kroll, T. (2013). Use of an Agile Bridge in the Development of Assistive Technology. In Proceedings of CHI 2013 (pp. 1579-1588). Paris, France: ACM. http://doi.org/978-1-4503-1899-0

SM91 González, C. S., Toledo, P., Muñoz, V., Noda, M. A., Bruno, A., \& Moreno, L. (2013). Inclusive educational software design with agile approach. In Proceedings of TEEM 2013 Conference (pp. 149-155). Salamanca, Spain: ACM. http://doi.org/10.1145/2536536.2536559

SM93 Sy, D. (2007). Adapting Usability Investigations for Agile User-centered Design. Journal of 
Usability Studies, 2(3), 112-132.

SM94 Budwig, M., Jeong, S., \& Kelkar, K. (2009). When User Experience Met Agile: A Case Study. In Proceedings of CHI 2009 Conference (pp. 3075-3083). Boston, MA: ACM. http://doi.org/978-160558-247-4/09/04

SM95 Prior, J. (2013). A sense of working there: The user experience of Agile software developers. In Proceedings of OZCHI 2013 Conference (pp. 147-150). Adelaide, Australia: ACM. http://doi.org/978-1-4503-2525-7/13/11

SM96 Asuncion, H., Socha, D., Sung, K., Berfield, S., \& Gregory, W. (2011). Serious Game Development as an Iterative User-Centered Agile Software Project. In Proceedings of GAS 2011 Conference (pp. 44-47). Waikiki, Honolulu, HI: ACM. http://doi.org/978-1-4503-0578-5/11/05

SM97 Liikkanen, L. A., Kilpiö, H., Svan, L., \& Hiltunen, M. (2014). Lean UX: The next generation of user-centered agile development? In Proceeding of the 8th Nordic Conference (pp. 1095-1100). Helsinki, Finland: ACM. http://doi.org/10.1145/2639189.2670285

SM98 Brown, D. D. (2013). Five Agile UX Myths. Journal of Usability Studies, 8(3), 55=60.

SM99 Au, I., Boardman, R., Jeffries, R., Larvie, P., Pavese, A., Riegelsberger, J., ... Stevens, M. (2008). User Experience at Google - Focus on the user and all else will follow. In Proceedings of CHI 2008 Conference (pp. 3681-3686). Florence, Italy: ACM. http://doi.org/978-1-60558-012-8/08/04

SM100 Koivisto, E. M. I., \& Suomela, R. (2007). Using Prototypes in Early Pervasive Game Development. In Proceedings of Sandbox Symposium 2007 (pp. 149-156). San Diego, CA. http://doi.org/978-1-59593-749-0/07/0008

SM101 Garnik, I., Sikorski, M., \& Cockton, G. (2014). Creative Sprints: An Unplanned Broad Agile Evaluation and Redesign Process. In Proceedings of the 8th Nordichi Conference (pp. 11251130). Helsinki, Finland: ACM. http://doi.org/10.1145/2639189.2670290

SM103 Rosemberg, C., \& Carvalho, M. De. (2010). MEX Experience Boards: A Set of Agile Tools for User Experience Design. In Proceedings of the IHC2010 Conference (pp. 213-216). Belo Horizonte, MG, Brazil: SBC.

SM104 Winter, J., \& Rönkkö, K. (2010). SPI success factors within product usability evaluation. The Journal of Systems and Software, 83, 2059-2072. http://doi.org/10.1016/j.jss.2010.04.066

SM105 Acuña, S. T., Castro, J. W., \& Juristo, N. (2012). A HCI technique for improving requirements elicitation. Information and Software Technology, 54(12), 1357-1375. http://doi.org/10.1016/j.infsof.2012.07.011

SM106 Seffah, A., Mohamed, T., Habieb-mammar, H., \& Abran, A. (2008). Reconciling usability and interactive system architecture using patterns. The Journal of Systems and Software, 81, 18451852. http://doi.org/10.1016/j.jss.2008.04.037

SM107 Cassino, R., Tucci, M., Vitiello, G., \& Francese, R. (2015). Empirical validation of an automatic usability evaluation method. Journal of Visual Languages and Computing, 28, 1-22. http://doi.org/10.1016/j.jvlc.2014.12.002

SM108 Propp, S., Buchholz, G., \& Forbrig, P. (2009). Integration of usability evaluation and model-based software development. Advances in Engineering Software, 40, 1223-1230. http://doi.org/10.1016/j.advengsoft.2009.01.025

SM109 Lindgaard, G. (2006). Notions of thoroughness, efficiency, and validity: Are they valid in HCI practice? International Journal of Industrial Ergonomics, 36(12), 1069-1074. http://doi.org/10.1016/j.ergon.2006.09.007

SM111 Queirós, A., Cerqueira, M., Martins, A. I., Silva, A. G., Alvarelhão, J., Teixeira, A., \& Rocha, N. P. (2014). ICF inspired Personas to improve development for usability and accessibility in Ambient Assisted Living. Procedia Computer Science, 27, 409-418. http://doi.org/10.1016/j.procs.2014.02.045

SM112 Molina, F., \& Toval, A. (2009). Integrating usability requirements that can be evaluated in design time into Model Driven Engineering of Web Information Systems. Advances in Engineering Software, 40, 1306-1317. http://doi.org/10.1016/j.advengsoft.2009.01.018

SM113 Juristo, N., Moreno, A. M., \& Sanchez-Segura, M.-I. (2007). Analysing the impact of usability on software design. Journal of Systems and Software, 80(9), 1506-1516. http://doi.org/10.1016/j.jss.2007.01.006

SM114 Delgado, A., Estepa, A., Troyano, J. A., \& Estepa, R. (2016). Reusing UI elements with ModelBased User Interface Development. Int $J$ Human-Computer Studies, 86, 48-62. 
http://doi.org/10.1016/j.ijhcs.2015.09.003

SM115 Chammas, A., Quaresma, M., \& Alvão, C. M. (2015). A Closer Look On The User Centred Design. Procedia Manufacturing, 3, 5397-5404. http://doi.org/10.1016/j.promfg.2015.07.656

SM116 Gómez, M., \& Cervantes, J. (2013). User Interface Transition Diagrams for customer - developer communication improvement in software development projects. The Journal of Systems and Software, 86, 2394-2410. http://doi.org/10.1016/j.jss.2013.04.022

SM118 Gil, M., Serral, E., Valderas, P., \& Pelechano, V. (2013). Designing for user attention: A method for supporting unobtrusive routine tasks. Science of Computer Programming, 78, 1987-2008. http://doi.org/10.1016/j.scico.2013.03.002

SM120 Butt, S. M., Onn, A., Butt, M. M., \& Tabassam, N. (2014). Towards a Model-Based Framework for Integrating Usability Evaluation Techniques in Agile Software Model. In Proceedings of Recent Advances on Soft Computing and Data Mining SCDM 2014 (pp. 561-570). http://doi.org/10.1007/978-3-319-07692-8

SM121 Cockton, G. (2016). Integrating Both User-Centred Design and Creative Practices into Agile Development. In G. Cockton, M. Lárusdóttir, P. Gregory, \& Å. Cajander (Eds.), Integrating UserCentered Design in Agile Development (pp. 249-276). Switzerland: Springer Nature. http://doi.org/10.1007/978-3-319-32165-3 11

SM123 Marcus, A., Ashley, J., Knapheide, C., Lund, A., Rosenberg, D., \& Vredenburg, K. (2009). A Survey of User-Experience Development at Enterprise Software Companies. In Proceedings of HCII 2009 Conference (pp. 601-610). Springer-Verlag Berlin Heidelberg.

SM124 Hussain, Z., Milchrahm, H., Shahzad, S., Slany, W., Tscheligi, M., \& Wolkerstorfer, P. (2009). Integration of Extreme Programming and User-Centered Design: Lessons Learned. In Proceedings of XP 2009 Conference (pp. 174-179). Springer-Verlag Berlin Heidelberg.

SM125 Gonçalves, J., \& Santos, C. (2011). POLVO - Software for Prototyping of Low-Fidelity Interfaces in Agile Development. In Proceedings of HCII 2011 Conference (pp. 63-71). Springer-Verlag Berlin Heidelberg.

SM126 Marca, D. A. (2013). SADT / IDEF0 for Augmenting UML, Agile and Usability Engineering Methods. In Escalona M.J., C. J., \& S. B. (Eds.), Proceedings of International Conference on Software and Data Technologies ICSOFT 2011 (pp. 38-55). Berlin, Heidelberg: Springer. http://doi.org/https://doi.org/10.1007/978-3-642-36177-7_3

SM127 Pyla, P. S., Pérez-quiñones, M. A., Arthur, J. D., \& Hartson, H. R. (2005). RIPPLE: An Event Driven Design Representation Framework for Integrating Usability And Software Engineering Life Cycles. In A. Seffah, J. Gulliksen, \& M. C. Desmarais (Eds.), Human-Centered Software Engineering - Integrating Usability in the Software Development Lifecycle. Human-Computer Interaction Series, vol $8 . \quad$ (pp. 245-265). Dordrecht: Springer. http://doi.org/https://doi.org/10.1007/1-4020-4113-6_13

SM128 Adikari, S., McDonald, C., \& Campbell, J. (2013). Reframed contexts: Design thinking for agile user experience design. In Proceedings of DUXU/HCII 2013 Conference (Vol. 8012 LNCS, p. 1-). Springer-Verlag Berlin Heidelberg. http://doi.org/10.1007/978-3-642-39229-0_1

SM129 Moreno, A. M., \& Yagiie, A. (2012). Agile User Stories Enriched with Usability. In Proceedings of XP 2012: Agile Processes in Software Engineering and Extreme Programming (pp. 168-176). Berlin, Heidelberg: Springer. http://doi.org/https://doi.org/10.1007/978-3-642-30350-0_12

SM130 Plonka, L., Sharp, H., Gregory, P., \& Taylor, K. (2014). UX design in agile: A DSDM case study. In G. Cantone \& M. Marchesi (Eds.), Proceedings of XP 2014: Agile Processes in Software Engineering and Extreme Programming (pp. 1-15). Cham: Springer. http://doi.org/10.1007/9783-319-06862-6_1

SM131 Hastreiter, I., Krause, S., Schneidermeier, T., \& Wolff, C. (2014). Developing UX for Collaborative Mobile Prototyping. In Proceedings of DUXU 2014 Conference (pp. 104-114). Switzerland: Springer.

SM132 Esteves, M., \& Andrade, V. (2011). Designing Interaction Concepts, Managing Customer Expectation and Mastering Agile Development in Rich Application Product Development. In Proceedings of HCII 2011 Conference (pp. 54-62). Berlin, Heidelberg: Springer.

SM134 Kuusinen, K. (2016). BoB: A Framework for Organizing Within-Iteration UXWork in Agile Development. In G. Cockton, M. Lárusdóttir, P. Gregory, \& Å. Cajander (Eds.), Integrating UserCentered Design in Agile Development (pp. 205-276). Switzerland: Springer Nature. http://doi.org/10.1007/978-3-319-32165-3_9 
SM135 Yambal, S. S., \& Munshi, S. (2009). Plugging the Holes: Increasing the Impact of User Experience Evaluations. In M. Kurosu (Ed.), Proceedings of HCII 2009 Conference (pp. 147156). Berlin, Heidelberg: Springer.

SM136 Zowghi, D., \& Coulin, C. (2005). Requirements Elicitation: A Survey of Techniques, Approaches, and Tools. In A. Aurum \& C. Wohlin (Eds.), Engineering and Managing Software Requirements (pp. 19-46). Berlin, Heidelberg: Springer. http://doi.org/10.1007/3-540-28244-0 2

SM137 van Loggem, B., \& van der Veer, G. (2014). A Documentation-Centred Approach to Software Design, Development and Deployment. In Proceedings of the 7th Workshop on Human-Computer Interaction and Visualization (HCIV) (pp. 188-200). Rostock, Germany: Springer Berlin Heidelberg.

SM139 Memmel, T., Gundelsweiler, F., \& Reiterer, H. (2007). Agile Human-Centered Software Engineering. In Proceedings of HCI 2007 Conference (pp. 1-9). Swinton, UK: British Computer Society.

SM140 Dighe, S., \& Joshi, A. (2014). An Autoethnographic Study of HCI Effort Estimation in Outsourced Software Development. In Proceedings of the 5th International Conference on Human-Centered Software Engineering (pp. 19-35). Paderborn: Springer.

SM141 Heimgärtner, R. (2007). A Tool for the Analysis of Cultural Differences in HCI. In N. Aykin (Ed.), Proceedings of HCII 2007 Conference (pp. 89-98). Springer-Verlag Berlin Heidelberg.

SM142 Maguire, M. (2001). Methods to support human-centred design. International Journal of HumanComputer Studies, 55(4), 587-634. http://doi.org/10.1006/ijhc.2001.0503 
Authors' Biographies

Abiodun Ogunyemi holds a Ph.D. from Tallinn University, Estonia. He currently works as a Project Specialist Usability/UX Studies at the same institution. He is a member of the Estonian ACM SIGCHI chapter (http://sigchi.org). His research interests are in humancentred software engineering, software process improvement and usability requirement elicitation.

David Lamas is a Professor of Interaction Design at Tallinn University's School of Digital Technologies, where he heads the Human-Computer Interaction (HCI) academic curates the Master in HCI. He also serves as the chair of the Estonian chapter of ACM's SIGCHI (http://sigchi.org), and as an expert member of IFIP's TC13 (http://ifiptc13.org).

Marta Lárusdóttir is an associate professor at the School of Computer Science at Reykjavik University, Iceland. Her main research focus is the integration of the user perspective in agile software development. Marta heads the CRESS research center at Reykjavik University (https://en.ru.is/cress) and is an expert member of IFIP's TC13 (http://ifip-tc13.org).

Dr. Fernando Loizides is Lecturer (Assistant Professor) in Computer Science and Informatics at Cardiff University, UK. His main research lies in Information Interaction and User Experience. He combines computer science with digital library research to investigate system enhancement using emerging technologies. He has applied development experience with several commercialized applications. 